\title{
Experimental determination of the temperature dependence of water activities for a selection of aqueous organic solutions
}

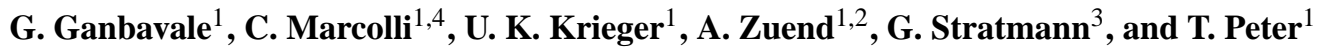 \\ ${ }^{1}$ Institute for Atmospheric and Climate Science, ETH Zurich, Zurich, Switzerland \\ ${ }^{2}$ Department of Atmospheric and Oceanic Sciences, McGill University, Montreal, Quebec, Canada \\ ${ }^{3}$ Department of Atmospheric Physics, DLR Oberpfaffenhofen, Germany \\ ${ }^{4}$ Marcolli Chemistry and Physics Consulting GmbH, Zurich, Switzerland \\ Correspondence to: C. Marcolli (claudia.marcolli@env.ethz.ch)
}

Received: 22 April 2014 - Published in Atmos. Chem. Phys. Discuss.: 19 May 2014

Revised: 18 August 2014 - Accepted: 22 August 2014 - Published: 19 September 2014

\begin{abstract}
This work presents experimental data of the temperature dependence of water activity in aqueous organic solutions relevant for tropospheric conditions (200-273 K). Water activity $\left(a_{\mathrm{w}}\right)$ at low temperatures $(T)$ is a crucial parameter for predicting homogeneous ice nucleation. We investigated temperature-dependent water activities, ice freezing and melting temperatures of solutions, and vapour pressures of a selection of atmospherically relevant aqueous organic systems. To measure $a_{\mathrm{w}}$ over a wide composition range and with a focus on low temperatures, we use various $a_{\mathrm{w}}$ measurement techniques and instruments: a dew point water activity meter, an electrodynamic balance (EDB), differential scanning calorimetry (DSC), and a setup to measure the total gas phase pressure at equilibrium over aqueous solutions. Water activity measurements were performed for aqueous multicomponent and multifunctional organic mixtures containing the functional groups typically found in atmospheric organic aerosols, such as hydroxyl, carboxyl, ketone, ether, ester, and aromatic groups. The aqueous organic systems studied at several fixed compositions over a considerable temperature range differ significantly in their temperature dependence. Aqueous organic systems of 1,4-butanediol and methoxyacetic acid show a moderate decrease in $a_{\mathrm{w}}$ with decreasing temperature. The aqueous M5 system (a multicomponent system containing five different dicarboxylic acids) and aqueous 2-(2-ethoxyethoxy)ethanol solutions both show a strong increase of water activity with decreasing temperature at high solute concentrations for $T<270 \mathrm{~K}$ and $T<260 \mathrm{~K}$, respectively. These measurements show that the temperature trend of $a_{\mathrm{w}}$ can be reversed at low temperatures
\end{abstract}

and that linear extrapolations of high-temperature data may lead to erroneous predictions. To avoid this, experimentally determined $a_{\mathrm{w}}$ at low temperature are needed to improve thermodynamic models towards lower temperatures and for improved predictions of the ice nucleation ability of organicwater systems.

\section{Introduction}

Organic compounds account for a large fraction of airborne particulate matter. They constitute around $50 \%$ of the total mass of the fine aerosol fraction in the continental midlatitudes (Saxena and Hildemann, 1996; Novakov et al., 1997; Murphy et al., 2006; Jimenez et al., 2009) while in the Tropics they may contribute up to $90 \%$ (Yamasoe et al., 2000; Roberts et al., 2002). In the upper troposphere a high fraction of organic aerosols are internally mixed with sulfate aerosols (Murphy et al., 2006, 2007). The organic aerosol fraction is expected to remain in a liquid or amorphous (viscous) state since the large number of organic compounds depresses the temperature at which crystallisation takes place (Marcolli et al., 2004). Studies show that the presence of an organic aerosol fraction may inhibit ice nucleation and growth (DeMott et al., 2003; Cziczo et al., 2004; Peter et al., 2006; Knopf and Lopez, 2009). The organic aerosol fraction contributes to aerosol effects in the atmosphere through interactions with water vapour, radiation, precipitation and trace gases (Fuzzi et al., 2006). In turn, these interactions influence the physical and chemical properties of aerosol particles 
such as physical state, hygroscopicity, size, and shape (e.g. Ming and Russell, 2002; Kanakidou et al., 2005; Zobrist et al., 2008; Ciobanu et al., 2009; Mikhailov et al., 2009; Reid et al., 2011; Song et al., 2012). The light scattering intensity of aerosols depends on growth and evaporation of the particles due to uptake and release of water vapour driven by changes in ambient relative humidity (RH) (Carrico et al., 2003; Baynard et al., 2006; Zieger et al., 2013). For an accurate description of this process, the hygroscopicity of the involved aerosol compositions have to be known. The hygroscopicities of most organic mixtures depend on temperature. Particle phase water activity $a_{\mathrm{w}}$ is equal to $\mathrm{RH}$, provided that the aqueous aerosol particles are in equilibrium with the surrounding gas phase and that they are sufficiently large so that the Kelvin effect is negligible. However, $a_{\mathrm{w}}$ data of aqueous organic compounds at low temperatures are scarce. Therefore, most estimates of the RH dependence of the direct aerosol effect rely on data at or close to room temperature. At low tropospheric temperatures, particle hygroscopicity may be different, because of the temperature dependence of $a_{\mathrm{w}}$ and/or water uptake and release may be retarded due to slow diffusion of water into highly viscous and amorphous phases (glasses) (Zobrist et al., 2008, 2011; Bones et al., 2012).

Homogeneous ice nucleation in the upper troposphere occurs in aqueous aerosol particles that subsequently grow into large ice crystals by deposition of water vapour, in part supplied from evaporating supersaturated cloud droplets. Unless solution droplets become glassy, homogeneous ice nucleation in supercooled aqueous solutions does not depend on the specific nature of the solute; rather, knowing the thermodynamic properties of the solution in terms of water activity $\left(a_{\mathrm{w}}\right)$ is sufficient, which implicitly accounts for specific properties of the solutes (Koop et al., 2000; Koop and Zobrist, 2009). Thus, $a_{\mathrm{w}}$ of solutions is a crucial parameter for homogeneous ice nucleation. Similarly, for heterogeneous freezing in immersion mode, $a_{\mathrm{w}}$-based models are applicable (Knopf and Alpert, 2013).

For a correct description of the ice nucleation process, deviations from ideal mixing in aqueous solutions droplets have to be taken into account. This is achieved by using activity coefficients to describe solution non-ideality. For water, with a thermodynamic activity defined on a mole fraction basis, its mole fraction-based activity coefficient is defined as $\gamma_{\mathrm{w}}=a_{\mathrm{w}} / x_{\mathrm{w}}$, where $x_{\mathrm{w}}$ is the mole fraction of water. Activity coefficients may exhibit considerable temperature dependence, which has to be parameterised explicitly in thermodynamic models in order to give accurate predictions for the level of non-ideality over a large range of temperatures. However, for aqueous organic solutions, thermodynamic models based on the UNIQUAC (UNIversal QUAsi Chemical) model (Abrams and Prausnitz, 1975) or its group contribution version UNIFAC (UNIquac Functional group Activity Coefficients) (Fredenslund et al., 1975) may not provide reliable predictions of activity coefficients when they are used outside the temperature range for which they have been pa- rameterised, i.e. at $T<275 \mathrm{~K}$ or $T>400 \mathrm{~K}$. Improvement of these models for atmospheric conditions is strongly limited by the limited availability of reliable activity coefficient data for $T<290 \mathrm{~K}$ (Saxena and Hildemann, 1997; Lohmann et al., 2001; Marcolli and Peter, 2005). Performing new $a_{\mathrm{w}}$ measurements by combining different measurement techniques (e.g. electrodynamic balance (EDB), differential scanning calorimetry (DSC), total gas phase pressure measurements) can provide the experimental data required for improved parameterisations of these thermodynamic models, especially for low temperatures. Studies of the temperature dependence of activity coefficients have been carried out for a few atmospherically relevant inorganic acids and salts such as $\mathrm{H}_{2} \mathrm{SO}_{4},\left(\mathrm{NH}_{4}\right)_{2} \mathrm{SO}_{4}$, and $\mathrm{NH}_{4} \mathrm{NO}_{3}$ (Knopf et al., 2003; Tang and Munkelwitz, 1993; Rodebush, 1918; Clegg et al., 1998), revealing quite distinct tendencies: $a_{\mathrm{w}}$ of dilute $\mathrm{H}_{2} \mathrm{SO}_{4}$ solutions are nearly independent of temperature, while in the case of $\mathrm{NH}_{4} \mathrm{NO}_{3}, a_{\mathrm{w}}$ increases with decreasing temperature (Koop, 2004).

For aqueous organic solutions, Zobrist et al. (2003) compared the $a_{\mathrm{w}}$ data of various poly(ethylene glycol) (PEG) solutions in the stable and supercooled range and noticed that the $a_{\mathrm{w}}$ of fixed-composition PEG solutions decreases with decreasing temperature. The influence of temperature on $a_{\mathrm{w}}$ becomes more pronounced with decreasing temperature as well as with increasing solute concentration. Zobrist et al. (2008) determined the temperature dependence of water activity coefficients in polyols and sugars at atmospheric pressure in the temperature range from the ice melting curve to $313 \mathrm{~K}$ and used these data to convert ice freezing temperatures from the mass fraction composition to the $a_{\mathrm{w}}$ scale. They found that if the temperature dependence is neglected, errors of the order of 10-15\% may result for $a_{\mathrm{w}}$ at the homogeneous ice freezing temperature. These examples show that in the case of aqueous organic solutions, the temperature dependence of $a_{\mathrm{w}}$ can be atmospherically important.

Low-temperature $a_{\mathrm{w}}$ data to the best of our knowledge are mostly restricted to solid-liquid equilibria (SLE). SLE measurements provide data on the melting curves of ice and/or the organic component, i.e. for the specific solution compositions referring to the solid-liquid phase boundary over a certain temperature range. To measure $a_{\mathrm{w}}$ at low temperatures over a wide composition and temperature range, we therefore combine different measurement techniques including a dew point water activity meter for $a_{\mathrm{w}}$ measurements at temperatures higher than $273 \mathrm{~K}$, differential scanning calorimetry (DSC) to determine SLE, and hygroscopicity measurements of single levitated particles in an electrodynamic balance (EDB). To complement these measurements, we developed a laboratory setup to measure total gas phase pressure over solutions at low temperatures. A detailed description of the measurement techniques is given in Sect. 2. Measurements were performed for binary aqueous organic mixtures covering functional groups and multifunctional organic compounds that are frequently observed in tropospheric 
aerosols. The organic functional groups considered include hydroxyl $(\mathrm{OH})$, carboxyl $(\mathrm{COOH})$, ketone $\left(\mathrm{CH}_{\mathrm{n}} \mathrm{CO}\right)$, ester $(\mathrm{CCOO})$, ether $\left(\mathrm{CH}_{\mathrm{n}} \mathrm{O}\right)$, aromatic carbon $\left(\mathrm{ACH}_{\mathrm{n}}\right)$ and aromatic carbon-alcohol ("phenol group", $\mathrm{ACOH}$ ), where "n" denotes the number of $\mathrm{H}$ atoms in the functional group. These new measurements provide useful data for the improvement of thermodynamic models and for applications in ice nucleation studies.

\section{Measurement techniques}

To perform measurements over a wide concentration and temperature range for atmospherically relevant organic compounds we use different measurement techniques, each of which covers a certain temperature range.

\subsection{Differential scanning calorimetry (DSC)}

Solid-liquid equilibria data were obtained by measuring the melting temperatures $\left(T_{\mathrm{m}}\right)$ of aqueous organic solutions for emulsified samples with a DSC instrument (Q10 from TA Instruments) following the procedure described in Zobrist et al. (2008). These measurements also provide homogeneous freezing temperatures $\left(T_{\mathrm{hom}}\right)$ as a function of aqueous solution composition. Water-in-oil emulsions with droplet diameters in the range of 0.5 to $5 \mu \mathrm{m}$ were prepared by adding four parts by volume of a $5 \mathrm{wt} \%$ lanolin/mineral oil solution (Fluka/Aldrich) to one part by volume of an aqueous solution and stirring with a rotor-stator homogeniser (Polytron PT 1300D with a PT-DA 1307/2EC dispersing aggregate) for $40 \mathrm{~s}$ at $7000 \mathrm{rpm}$. Samples ( 8 to $10 \mathrm{mg}$ ) were pipetted into the DSC pans, which were immediately sealed to prevent any evaporation. All aqueous solutions were made with distilled and deionised water (resistivity $>18.2 \mathrm{M} \Omega \mathrm{cm}$, total organic impurities $<5 \mathrm{ppb}$ ). Each experiment comprised three subsequent cooling cycles starting from $293 \mathrm{~K}$. The first and the last cycle were run with a cooling rate of $10 \mathrm{~K} \mathrm{~min}^{-1}$ (used as control for the emulsion stability) and the second cycle with a cooling rate of $1 \mathrm{~K} \mathrm{~min}^{-1}$ (used for the melting and freezing point evaluation). Ice melting temperatures were evaluated at the melting peak maxima of the heating cycle run at a rate of $1 \mathrm{~K} \mathrm{~min}^{-1}$. A detailed calibration of the DSC resulted in a maximum uncertainty for ice melting temperatures of $\pm 0.8 \mathrm{~K}$ (Zobrist et al., 2008).

Aqueous solutions of the following organic compounds were investigated: 1,3-propanediol (Aldrich, 98\%), 1,5pentanediol (Fluka, $\geq 97 \%$ ), 1,2-hexanediol (Aldrich, 97\%), glycolic acid (Aldrich, 99\%), pyruvic acid (Aldrich, 99\%), methoxyacetic acid (Aldrich, 99\%), 2-ethoxyethyl acetate (Aldrich, 99\%), D-sorbitol (Aldrich, $\geq 98 \%$ ), sucrose (sigma, $\geq 99 \%$ ), resorcinol (Aldrich, 99\%), 2-(2ethoxyethoxy)ethanol (Aldrich, $\geq 99 \%$ ) and M5, a multicomponent dicarboxylic acid mixture composed of DLmalic acid (Aldrich, 99\%), maleic acid (Aldrich, 99\%), mal- onic acid (Aldrich, $99 \%$ ), glutaric acid (Aldrich, 99\%) and methylsuccinic acid (Aldrich, $99 \%$ ). Table 1 lists the compounds used together with a selection of their physical properties. The ice melting $\left(T_{\mathrm{m}}\left(x_{\mathrm{org}}\right)\right)$ and homogeneous freezing temperatures $T_{\mathrm{hom}}\left(x_{\mathrm{org}}\right)$, obtained by DSC measurements for the aqueous organic mixtures at different liquid solution compositions given as mole fraction of the organic component, $x_{\text {org }}$, are provided in Table 2.

We use the parameterisation by Koop and Zobrist (2009) to calculate $a_{\mathrm{w}}$ at the melting temperature of ice for a known solution composition. The vapour pressures for solid phase (superscript $\mathrm{S}$ ) pure hexagonal ice, $p_{\text {ice }}^{\circ}, \mathrm{S}\left(=p_{\mathrm{w}}^{\circ}, \mathrm{S}\right)$, and water in equilibrium with the liquid (superscript $\mathrm{L}$ ) solution, $p_{\mathrm{w}}^{\mathrm{L}}$, on the melting curve (SLE) are the same:

$p_{\mathrm{w}}^{\mathrm{L}}\left(T=T_{\mathrm{m}}\left(x_{\mathrm{org}}\right)\right)=p_{\text {ice }}^{\circ}, \mathrm{S}\left(T=T_{\mathrm{m}}\left(x_{\mathrm{org}}\right)\right)$,

where vapour-liquid, vapour-solid, and solid-liquid equilibria exist. At SLE, the water activity of the aqueous organic solution, $a_{\mathrm{w}}^{\mathrm{SLE}}(T, p)$, in equilibrium with ice can therefore be expressed by

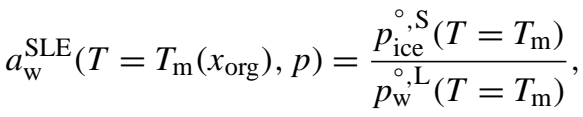

where $p_{\mathrm{w}}^{\circ} \mathrm{L}\left(T=T_{\mathrm{m}}\right)$ is the vapour pressure of pure liquid (supercooled) water at $T_{\mathrm{m}}$.

We use the Koop and Zobrist (2009) temperaturedependent parameterisation which is based on Murphy and Koop (2005) to calculate $a_{\mathrm{w}}$ at SLE, valid at low (ambient) pressure in the temperature range $173 \mathrm{~K}<T<273.15 \mathrm{~K}$ :

$$
\begin{aligned}
a_{\mathrm{w}}^{\mathrm{SLE}}(T, p) & =[\exp (9.550426-5723.265 / T+3.53068 \cdot \ln (T) \\
& -0.00728332 \cdot T)] \cdot[\exp (54.842763-6763.22 / T \\
& -4.210 \cdot \ln (T)+0.000367 \cdot T+\tanh (0.0415 \\
& \cdot(T-218.8)) \cdot(53.878-1331.22 / T-9.44523 \\
& \cdot \ln (T)+0.014025 \cdot T))]^{-1} .
\end{aligned}
$$

\subsection{Water activity measurements}

Water activity measurements were performed using an AquaLab water activity meter (Model 3B, Decagon Devices, USA). The instrument employs the chilled mirror method to determine the dew point temperature of the gas phase in equilibrium with the sample. Infrared thermometry in addition indicates the sample temperature. This instrument allows $a_{\mathrm{w}}$ measurements in the temperature range from 288 to $313 \mathrm{~K}$ for bulk samples. For most measurements the volatile sample block available as an accessory with the instrument was used since several of the organic compounds used have rather low, but potentially significant vapour pressures at the probed temperatures. Experimental errors for the volatile sample block are specified as $\pm 0.015 a_{\mathrm{w}}$ by the manufacturer. The sample block was frequently calibrated and corrected for drifts and offsets using saturated salt solutions 
Table 1. Selected physical properties of organic components used for the experiments: molar mass $(M)$, melting point ( $\left.T_{\mathrm{m}}\right)$, boiling point $\left(T_{\mathrm{b}}\right)$ at standard pressure $(101.325 \mathrm{kPa})$, and structure.

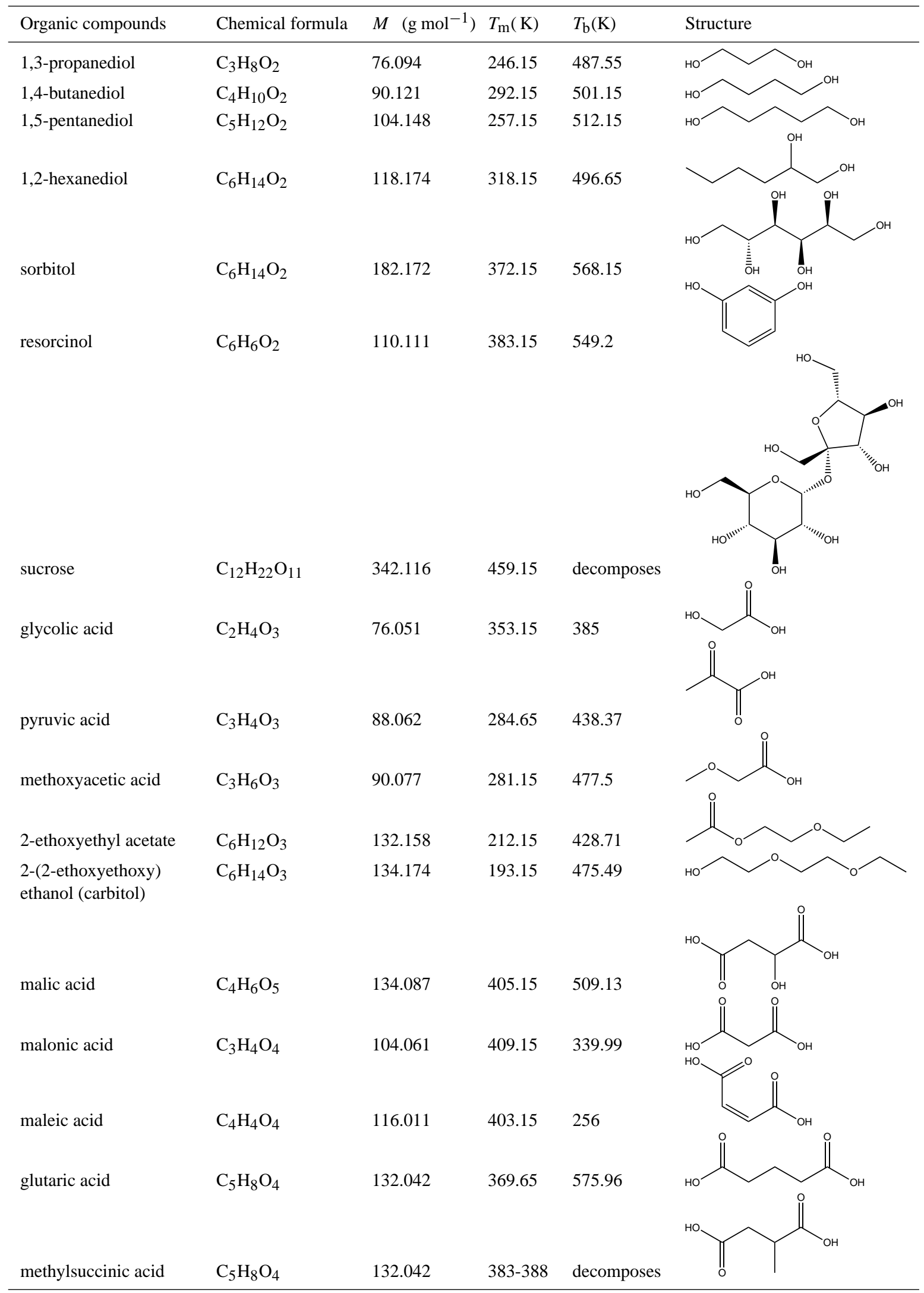


Table 2. Homogeneous ice freezing $T_{\text {hom }}\left(x_{\mathrm{org}}\right)$ and ice melting $T_{\mathrm{m}}\left(x_{\mathrm{org}}\right)$ temperatures of the investigated aqueous organic solutions. Solution compositions are expressed in mole fraction $x$ (organic) and temperature in $\mathrm{K}^{*}{ }^{*}$

\begin{tabular}{|c|c|c|c|c|c|}
\hline$x(1,3$-propanediol $)$ & $T_{\text {hom }}\left(x_{\text {org }}\right)$ & $T_{\mathrm{m}}\left(x_{\mathrm{org}}\right)$ & $x(1,5$-pentanediol $)$ & $T_{\text {hom }}\left(x_{\text {org }}\right)$ & $T_{\mathrm{m}}\left(x_{\mathrm{org}}\right)$ \\
\hline 0.02637 & 231.23 & 270.47 & 0.01924 & 232.38 & 271.90 \\
\hline 0.05656 & 223.55 & 266.78 & 0.04240 & 225.04 & 269.23 \\
\hline 0.09225 & 212.74 & 262.08 & 0.06971 & 214.41 & 266.51 \\
\hline \multirow[t]{2}{*}{0.13630} & 200.20 & 255.69 & 0.10300 & 200.14 & 263.28 \\
\hline & & & 0.15035 & & 259.59 \\
\hline$x$ (glycolic acid) & $T_{\text {hom }}\left(x_{\text {org }}\right)$ & $T_{\mathrm{m}}\left(x_{\mathrm{org}}\right)$ & $x$ (pyruvic acid) & $T_{\text {hom }}\left(x_{\text {org }}\right)$ & $T_{\mathrm{m}}\left(x_{\mathrm{org}}\right)$ \\
\hline 0.02549 & 230.37 & 270.54 & 0.02223 & 231.72 & 270.76 \\
\hline 0.05612 & 224.03 & 267.46 & 0.04879 & 223.68 & 267.06 \\
\hline 0.09191 & 217.77 & 262.99 & 0.08090 & 210.84 & 261.65 \\
\hline 0.13601 & 205.90 & 258.56 & 0.12026 & 209.45 & 253.58 \\
\hline$x(1,2$-hexanediol $)$ & $T_{\text {hom }}\left(x_{\text {org }}\right)$ & $T_{\mathrm{m}}\left(x_{\mathrm{org}}\right)$ & $x$ (sucrose) & $T_{\text {hom }}\left(x_{\text {org }}\right)$ & $T_{\mathrm{m}}\left(x_{\mathrm{org}}\right)$ \\
\hline 0.01664 & 232.13 & 271.57 & 0.01040 & 232.00 & 272.00 \\
\hline 0.03658 & 225.01 & 271.54 & 0.01624 & 230.68 & 271.34 \\
\hline 0.06099 & 223.21 & 271.32 & 0.02303 & 227.51 & 270.35 \\
\hline 0.09197 & 223.17 & 271.05 & 0.03056 & 225.33 & 269.08 \\
\hline 0.13202 & 222.20 & 270.69 & 0.03937 & 221.09 & 267.75 \\
\hline 0.18637 & 221.35 & 269.71 & 0.04870 & 217.10 & 265.75 \\
\hline \multirow[t]{2}{*}{0.25834} & 216.14 & 267.46 & 0.06064 & & 263.15 \\
\hline & & & 0.07317 & & 260.95 \\
\hline$x$ (methoxyacetic acid) & $T_{\text {hom }}\left(x_{\text {org }}\right)$ & $T_{\mathrm{m}}\left(x_{\mathrm{org}}\right)$ & $x$ (sorbitol) & $T_{\text {hom }}\left(x_{\text {org }}\right)$ & $T_{\mathrm{m}}\left(x_{\mathrm{org}}\right)$ \\
\hline 0.02180 & 231.96 & 271.48 & 0.01103 & 233.35 & 272.19 \\
\hline 0.04757 & 224.69 & 268.98 & 0.02422 & 230.00 & 270.63 \\
\hline 0.07904 & 218.43 & 265.95 & 0.04077 & 225.40 & 268.68 \\
\hline 0.11765 & 208.79 & 262.64 & 0.06174 & 218.67 & 265.94 \\
\hline 0.16709 & 193.55 & 257.67 & 0.08948 & 208.42 & 261.84 \\
\hline 0.22937 & & 251.31 & 0.12867 & & 255.75 \\
\hline$x($ resorcinol $)$ & $T_{\text {hom }}\left(x_{\text {org }}\right)$ & $T_{\mathrm{m}}\left(x_{\mathrm{org}}\right)$ & $x$ (2-ethoxyethyl acetate) & $T_{\text {hom }}\left(x_{\text {org }}\right)$ & $T_{\mathrm{m}}\left(x_{\mathrm{org}}\right)$ \\
\hline 0.01818 & 231.55 & 271.98 & 0.01516 & 232.65 & 272.24 \\
\hline 0.03956 & 228.20 & 270.67 & 0.03318 & 228.62 & 271.22 \\
\hline 0.06567 & 226.60 & 268.84 & 0.05509 & 207.81 & 270.75 \\
\hline 0.09848 & 223.28 & 267.15 & & & \\
\hline$x$ (2-(2-ethoxyethoxy)ethanol) & $T_{\text {hom }}\left(x_{\mathrm{org}}\right)$ & $T_{\mathrm{m}}\left(x_{\mathrm{org}}\right)$ & & & \\
\hline 0.01463 & 232.52 & 272.03 & & & \\
\hline 0.03245 & 224.30 & 269.16 & & & \\
\hline 0.05412 & 210.51 & 265.18 & & & \\
\hline 0.08215 & & 259.56 & & & \\
\hline
\end{tabular}

* The accuracies of the freezing and melting point measurements are $\pm 0.5 \mathrm{~K}$ and $\pm 0.4 \mathrm{~K}$, respectively.

and distilled water samples covering the relevant $a_{\mathrm{w}}$ range. For solutions of low-volatility organic compounds and water, the standard sample block was used with a specified accuracy of $\pm 0.003 a_{\mathrm{w}}$. Table 3 provides measured bulk solution $a_{\mathrm{w}}$ data for sorbitol, resorcinol, glycolic acid, pyruvic acid and sucrose at $298.15 \mathrm{~K}$. For some selected systems additional bulk $a_{\mathrm{w}}$ measurements at $279 \mathrm{~K}$ were carried out by turning off the temperature control within the AquaLab instrument and performing the measurements in a cold room at a constant temperature of $279 \mathrm{~K}$ (with an uncertainty in room temperature of $\pm 0.5 \mathrm{~K}$ ). Water activity measurements were performed for aqueous solutions of 1,4-butanediol, M5, methoxyacetic acid, and 2-(2-ethoxyethoxy)ethanol, for the temperature range $279 \mathrm{~K}$ to $313 \mathrm{~K}$.

\subsection{Electrodynamic balance (EDB) measurements}

The basic experimental setup has been described previously (Krieger et al., 2000; Zobrist et al., 2011). An electrically charged particle (typically $2-20 \mu \mathrm{m}$ in radius) is levitated in 
Table 3. Bulk water activity $\left(a_{\mathrm{W}}\right)$ measurements* at $298.15 \mathrm{~K}$ of different aqueous organic solutions. Solution compositions are expressed in mole fraction $x$ (organic).

\begin{tabular}{cccccccccc}
\hline$x$ (sorbitol) & $a_{\mathrm{W}}$ & $x$ (resorcinol) & $a_{\mathrm{W}}$ & $x$ (glycolic acid) & $a_{\mathrm{W}}$ & $x$ (pyruvic acid) & $a_{\mathrm{W}}$ & $x($ sucrose $)$ & $a_{\mathrm{W}}$ \\
\hline 0.01103 & 0.981 & 0.01818 & 0.985 & 0.02564 & 0.962 & 0.02267 & 0.966 & 0.01040 & 0.992 \\
0.02422 & 0.956 & 0.03956 & 0.950 & 0.05588 & 0.934 & 0.04868 & 0.925 & 0.01624 & 0.988 \\
0.04077 & 0.934 & 0.06567 & 0.938 & 0.09209 & 0.887 & 0.08068 & 0.883 & 0.02303 & 0.977 \\
0.06174 & 0.898 & 0.09848 & 0.893 & 0.13644 & 0.838 & 0.12020 & 0.836 & 0.03056 & 0.971 \\
0.08948 & 0.834 & 0.13992 & 0.877 & 0.19154 & 0.767 & 0.16986 & 0.778 & 0.03937 & 0.955 \\
0.12867 & 0.752 & 0.19312 & 0.843 & 0.25957 & 0.665 & 0.23467 & 0.704 & 0.04870 & 0.939 \\
0.18723 & 0.621 & 0.27629 & 0.836 & 0.35447 & 0.570 & 0.32089 & 0.596 & 0.06064 & 0.914 \\
& & & & 0.48560 & 0.451 & 0.45005 & 0.434 & 0.07317 & 0.888 \\
& & & & & & 0.61773 & 0.193 & 0.16527 & 0.692 \\
\hline
\end{tabular}

* The accuracy of the water activity measurements is specified by the manufacturer as \pm 0.015 (absolute range) in $a_{\mathrm{w}}$.

an electrodynamic balance. The balance is hosted within a three-wall glass chamber with a cooling agent flowing between the inner walls and an insulation vacuum between the outer walls. A constant flow of a $\mathrm{N}_{2} / \mathrm{H}_{2} \mathrm{O}$ mixture with a controlled $\mathrm{H}_{2} \mathrm{O}$ partial pressure is pumped continuously through the chamber at a constant total pressure, adjustable between 20 and $100 \mathrm{kPa}$. A charged, liquid particle is injected in the trap using a single-particle generator (HewlettPackard 51633A ink jet cartridge) and is levitated in the balance, while keeping the temperature constant and increasing or decreasing the relative humidity within the chamber continuously. This is achieved by changing the $\mathrm{N}_{2} / \mathrm{H}_{2} \mathrm{O}$ ratio in the gas phase, using automatic mass flow controllers. The humidity sensor placed close to the particle registers the RH with an accuracy of $\pm 1.5 \%$ RH (UPSI, France, Model G-TUS.13) between 10 and $90 \%$ RH. The sensor was calibrated directly in the trap using the deliquescence relative humidity of different salts at different temperatures in the range of interest. The concentration of the particle can be calculated from the DC voltage compensating the gravitational force when the dry particle mass is known (measured at $\mathrm{RH}<10 \%$ ). An alternative, independent measure of concentration is based on Mie resonance spectroscopy. We use a ball lens type point source LED as a "white light" source to focus the light on the levitated particle and a pierced mirror to collect Mie resonance spectra in a backscattering geometry. Radius information is retrieved from the Mie resonance spectra as described by Zobrist et al. (2011). To convert radius to mass and concentration, we assume ideal volume mixing (linear additivity of molar volumes) to calculate the density of aqueous solutions. For the M5 mixture we use a molar volume of $86.62 \mathrm{~cm}^{3} \mathrm{~mol}^{-1}$ and a molarity based linear parameterisation to calculate the refractive index, $n_{\mathrm{D}}$, at $589 \mathrm{~nm}$ for aqueous M5 solutions of different concentrations $\left(n_{\mathrm{D}}=1.3334+0.01297 \times\right.$ molarity $)$. Since the optically retrieved concentration data are less noisy and more stable with respect to drifts over longer measurement periods, we use those for the water activity versus concentration data presented in Tables 10 and 11.

\subsection{Total gas phase pressure measurements}

We use total gas phase pressure measurements of binary aqueous organic solutions to determine $a_{\mathrm{w}}$ at low temperatures over a wide concentration range. The organic components of the binary systems were selected such that their vapour pressure contribution to the total pressure is irrelevant, i.e. substantially lower than the vapour pressure of water in the considered temperature range. Given this prerequisite, measured total pressures can be evaluated as being the vapour pressures of water in vapour-liquid equilibrium with the binary solutions at measured temperatures and known compositions. Since we attribute measured total pressures entirely to water vapour, we are restricted to binary mixtures with low organic vapour pressures that lie within or below the measurement uncertainty of the total pressure over the whole investigated composition range. The experimental setup used for the total gas phase pressure measurements is shown in Fig. 1.

The setup consists of a round-bottom flask $(500 \mathrm{~mL})$ in which an aqueous organic mixture of a particular composition is filled. For the total gas phase pressure measurements, the flask is immersed in a thermostated ethanol bath (initially set to $223 \mathrm{~K}$ ) whose temperature is slowly ramped up to $290 \mathrm{~K}$. The flask can be evacuated to $\sim 10^{-6} \mathrm{~Pa}$ using a vacuum pump and cooled in liquid $\mathrm{N}_{2}$ for the purpose of degassing residual air naturally present in the samples. Glass beads ( $\sim 50 \mathrm{~g}, \sim 3 \mathrm{~mm}$ diameter) are added to the flask to prevent undesirable foaming of the solution during degassing cycles, which may occur when a frozen solution thaws relatively quickly at room temperature after cooling to liquid nitrogen temperature. Foaming may often lead to splashing of solution droplets up to the neck of the flask, where the droplets remain without contact to the rest of the sample. If such droplets were present above the level of the ethanol bath into which the flask is submerged to maintain 


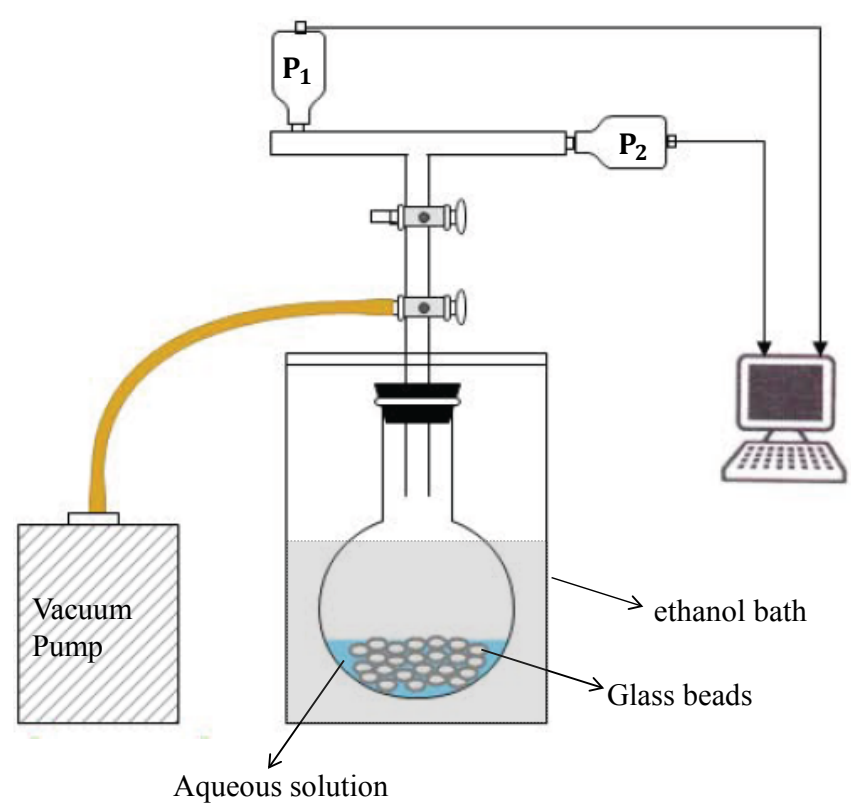

Figure 1. Setup for total gas phase pressure measurements of aqueous organic solutions at room temperature and below.

a temperature-controlled environment (Julabo, FP50 thermostat), they would be at a different temperature than the bulk solution and present a cause of systematic errors. The pressure increase during the temperature ramp is registered by two pressure heads operating in the pressure ranges $P_{1}$ (Pfeiffer Vacuum, CMR-262, range: 1 to $1 \times 10^{4} \mathrm{~Pa}$ ) and $P_{2}$ (Pfeiffer Vacuum, PKR-251, range: $1 \times 10^{-2}$ to $110 \mathrm{~Pa}$ ).

A typical experiment involves the following operational procedure. A binary aqueous solution mixture (volume of 3 to $5 \mathrm{~mL}$ ) is added to the flask. To remove the residual gases (e.g. $\mathrm{N}_{2}, \mathrm{O}_{2}$, Ar, and $\mathrm{CO}_{2}$ ) from the solution, a thorough degassing procedure is carried out for which the flask is placed in a liquid $\mathrm{N}_{2}$ bath (at $T \approx 77 \mathrm{~K}$ ) and the valve to the vacuum pump is opened to remove the gas phase above the solution until a low pressure of $\sim 10^{-6} \mathrm{~Pa}$ is reached. Thereafter, the valve is closed again and the solution is slowly brought back to room temperature. These warming and cooling cycles are carried out about 2-3 times so that all the residual gases are removed. These degassing cycles are assumed to lead only to a very small loss of water via the gas phase, so that the mixture composition remains practically unaffected. Before the actual measurement starts, the sample flask is once more cooled in liquid $\mathrm{N}_{2}$ and then transferred to the ethanol bath, which is held at $223 \mathrm{~K}$, and further evacuated until a constant pressure is reached to allow the removal of any remaining dissolved gases from the solution and ensuring that the total pressure measured by the pressure sensors corresponds, within uncertainty, to the one of water vapour alone. The valves to the pressure heads are then opened and the total gas phase pressure measurement is carried out in the temperature range from 228 to $290 \mathrm{~K}$ by increasing the temper- ature of the ethanol bath at a constant rate of $10.6 \mathrm{~K} \mathrm{~h}^{-1}$, over a time period of $350 \mathrm{~min}$. The measured constant leak rate of the instrument, which we measured for the same time interval as the actual experiment, is subtracted from the total pressure data and from the resulting values, water vapour pressure data for the particular system compositions and temperatures are obtained. Pure water ice was measured as a reference sample. From this we estimate the error in the measured water activity to be \pm 0.015 . For the investigated systems, $a_{\mathrm{w}}$ values are derived by dividing the measured water vapour pressure by the calculated liquid-state vapour pressure of pure water (liquid-state saturation vapour pressure) at the prescribed temperature of the ethanol bath using the parameterisation by Murphy and Koop (2005). We conservatively estimate the uncertainty in the water activity in organic solutions to be twice of that determined for pure water ice, namely \pm 0.03 in absolute $a_{\mathrm{w}}$, to account for possible artefacts by residual foaming and/or temperature gradients due to the glass beads.

\section{Results}

The total gas phase pressure measurements were performed for four aqueous organic mixtures, namely for aqueous solutions of 1,4-butanediol, M5, methoxyacetic acid and 2-(2ethoxyethoxy)ethanol. These measurements were complemented by bulk solution $a_{\mathrm{w}}$ measurements using the water activity meter in the temperature range from $313 \mathrm{~K}$ to $279 \mathrm{~K}$, and SLE ice melting and freezing data measured with the DSC in the temperature range from $273 \mathrm{~K}$ to $\sim 200 \mathrm{~K}$, to obtain $a_{\mathrm{w}}$ data coverage over a wide range of temperatures and concentrations. In the case of aqueous M5 mixtures, additional $a_{\mathrm{w}}$ measurements to temperatures as low as $233 \mathrm{~K}$ were obtained from single-particle measurements using the EDB.

\subsection{1,4-Butanediol}

Figure 2 shows $a_{\mathrm{w}}$ measurements for aqueous 1,4-butanediol solutions obtained from the different measurement techniques. The ice melting curve as a function of $a_{\mathrm{w}}$ (dashed blue curve) is calculated using the parameterisation by Koop and Zobrist (2009). The dash-dotted lines represent the parameterisation by Zobrist et al. (2008) for the different compositions given in terms of mass percent (wt \%). Zobrist et al. (2008) used experimental ice melting temperatures and bulk $a_{\mathrm{w}}$ data and applied a composition- and temperaturedependent parameterisation for water activities of specific mixtures with seven coefficients fitted to their data sets. The solid lines (both coloured and grey) show the derived $a_{\mathrm{w}}$ values from the total gas phase pressure measurements for concentrations from 20 to $90 \mathrm{wt} \%$ over a temperature range from 240 to $290 \mathrm{~K}$. The measured data are considered reliable within the uncertainty of the method $\left( \pm 0.03\right.$ of $\left.a_{\mathrm{w}}\right)$. The 


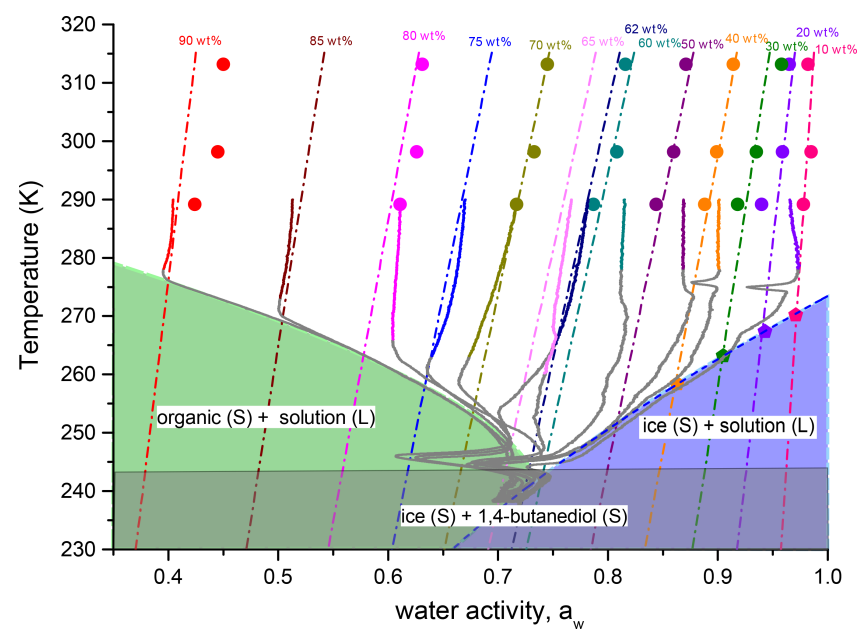

Figure 2. Measured water activities of aqueous 1,4-butanediol solutions vs. temperature. The different colours indicate the solution compositions in wt \% of the organic component. The solid curves show data derived from the total gas phase pressure measurements. The coloured portion of the solid curves represents the temperature range for which the measurements are considered reliable within the uncertainty of the method ( \pm 0.03 of $a_{\mathrm{W}}$ ). Water activities derived from DSC measurements on the ice melting curve are represented by pentagons. Bulk $a_{\mathrm{w}}$ measurements using the water activity meter are represented by solid circles. The dash-dotted lines show the composition- and temperature-dependent $a_{\mathrm{w}}$ parameterisation by Zobrist et al. (2008). The blue dashed line is the ice melting curve (Koop and Zobrist, 2009). In the colour-shaded regions one or both components are supersaturated with respect to the solid phase and therefore, above the eutectic temperature ( $\sim 243-245 \mathrm{~K})$, at equilibrium one solid phase coexists with the remaining solution.

grey part of these lines do not reflect the $a_{\mathrm{w}}$ of the solutions; rather, they are substantially influenced by the presence of solid phases and/or reflect undesired partial pressure contributions from residual gases $\left(\mathrm{N}_{2}, \mathrm{O}_{2}\right)$, which may be present to a small extent in the solutions even after several cycles of degassing. Such artefacts caused by residual, highly volatile (supercritical) gases become much more important towards low temperatures relative to the much lower partial pressure signal from water, essentially enlarging the uncertainties of the derived water activities beyond a practical limit for a meaningful data evaluation. The grey portions of the curves merge within uncertainty on the SLE phase boundary of the aqueous solution and ice for $a_{\mathrm{w}}>0.76$ and analogously on the 1,4-butanediol SLE line for $a_{\mathrm{w}}<0.70$. Eutectic melting is observed at $\sim 243$ to $245 \mathrm{~K}$ as a horizontal peak to low $a_{\mathrm{w}}$ because the sample temperature remains constant during the melting process while the prescribed temperature in the surrounding ethanol bath, which is used to derive the $a_{\mathrm{w}}$ data shown in Fig. 2, keeps increasing. The area of the phase diagram below the melting curve of one of the components, i.e. the green and blue shaded areas, is not accessible for $a_{\mathrm{w}}$ measurements by bulk techniques, because the presence of solid phases alters the initial (known) composition of the remaining liquid solution. The dips visible on the curves around $T \approx 275 \mathrm{~K}$ of the total gas phase pressure measurements of the 20 and $40 \mathrm{wt} \%$ mixtures are artefacts, which are probably due to the melting of tiny droplets that may have splashed to the neck of the flask while degassing the solution prior to the actual measurements.

All measurements taken together provide a consistent picture of the temperature dependence of $a_{\mathrm{w}}$ of aqueous 1,4butanediol, namely a more or less constant decrease of $a_{\mathrm{w}}$ with decreasing temperature, which is well described by the parameterisation of Zobrist et al. (2008) (for bulk solutions at least until the intersection with the melting curves). Table 4 provides $a_{\mathrm{w}}$ data obtained from the AquaLab water activity meter. Table 12 lists the $a_{\mathrm{w}}$ data derived from the total gas phase pressure measurements.

\subsection{Methoxyacetic acid}

Figure 3 shows $a_{\mathrm{w}}$ measurements of aqueous methoxyacetic acid covering the concentration range from 10 to $90 \mathrm{wt} \%$ and temperatures from 240 to $298 \mathrm{~K}$ using different experimental techniques. Water activity of the aqueous solution in equilibrium with ice, i.e. SLE for concentrations from 10 to $60 \mathrm{wt} \%$ covering a temperature range of 251 to $272 \mathrm{~K}$, are obtained using DSC measurements (pentagons). The grey solid lines at lower concentrations represent the $a_{\mathrm{w}}$ data derived from total gas phase pressure measurements which merge on the ice melting curve $\left(a_{\mathrm{w}}>0.8\right)$, while the grey solid lines at higher concentrations $\left(a_{\mathrm{w}}<0.7\right)$ follow the melting curve of methoxyacetic acid. Eutectic melting is observed at $T \approx 253 \mathrm{~K}$. The colour-shaded region below the ice-melting and the methoxyacetic acid melting curves are not accessible for total gas phase pressure measurements, because the presence of solid phases influences the solution concentration (above the eutectic melting line), due to which the measured $a_{\mathrm{w}}$ will not correspond to the initial composition of the solution being measured. The broad horizontal peaks to high $a_{\mathrm{w}}$ on the 50,60, and $70 \mathrm{wt} \%$ lines of the total gas phase pressure measurements indicate an increased total pressure whose origin is unclear, but which points to artefacts (perhaps due to the melting of small solution droplets, splashed to the neck of the glass flask, that are of lower organic concentrations and/or at higher temperature).

The measured $a_{\mathrm{w}}$ using the water activity meter and the $a_{\mathrm{W}}$ data derived from total pressure measurements indicate a small temperature dependence and are consistent within 2 to $5 \%$ at higher concentration wt $\%$ of methoxyacetic acid. A reason for this deviation might be that full equilibration of the solution was not reached after the melting of solid methoxyacetic acid over the timescale of the experiment. In the more dilute composition range with respect to the organic component, deviations $<2 \% a_{\mathrm{w}}$ are found, indicating the validity of the total pressure data in the temperature range considered reliable. Measurements and the 


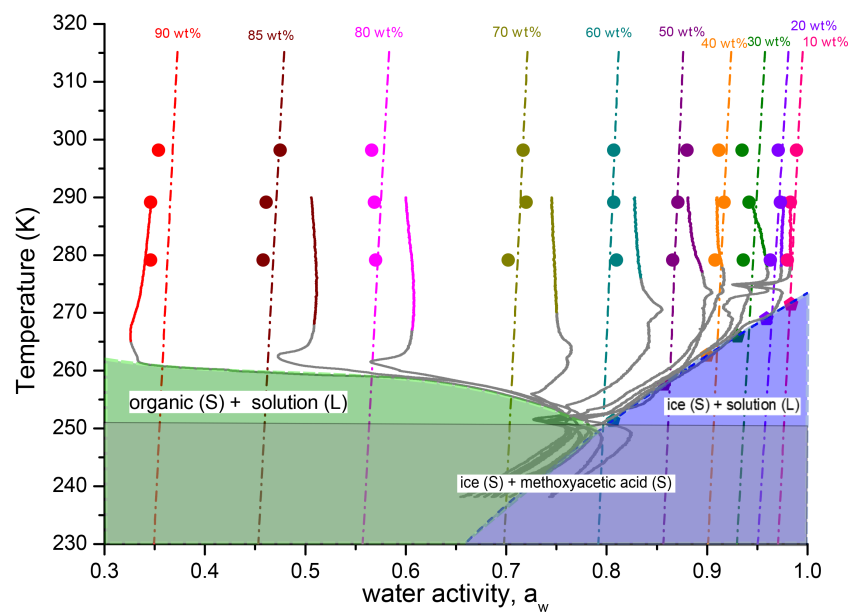

Figure 3. Measured water activities of aqueous methoxyacetic acid solutions vs. temperature. The different colours indicate the solution compositions in wt $\%$ of the organic component. The solid curves show data derived from the total gas phase pressure measurements. The coloured portion of the solid curves represents the temperature range for which the measurements are considered reliable within the uncertainty of the method ( \pm 0.03 of $a_{\mathrm{W}}$ ). Water activities derived from DSC measurements on the ice melting curve are represented by pentagons. Bulk $a_{\mathrm{w}}$ measurements using the water activity meter are represented by solid circles. The dash-dotted lines show the composition- and temperature-dependent $a_{\mathrm{w}}$ parameterisation by Zobrist et al. (2008). The blue dashed line is the ice melting curve (Koop and Zobrist, 2009). In the colour-shaded regions one or both components are supersaturated with respect to the solid phase and therefore, above the eutectic temperature $(\sim 251 \mathrm{~K})$, at equilibrium one solid phase coexists with the remaining solution.

parameterisation for the temperature dependence of water activity by Zobrist et al. (2008) (dash-dotted lines in Fig. 3) indicate a small $a_{\mathrm{w}}$ decrease with the decrease in the temperature. The bulk $a_{\mathrm{w}}$ data from the water activity meter measurements is provided in Table 5. The calculated $a_{\mathrm{w}}$ data obtained from the total pressure experiments for various solution compositions are given in Table 13.

\subsection{2-(2-Ethoxyethoxy)ethanol}

Water activity measurements for aqueous solutions of 2-(2ethoxyethoxy)ethanol (also known as carbitol) in the concentration range from 10 to $90 \mathrm{wt} \%$ of organic and the temperature range from 230 to $298 \mathrm{~K}$ are presented in Fig 4. DSC measurements were performed for a concentration range of 10 to $40 \mathrm{wt} \%$ covering the temperature range from 210 to $272 \mathrm{~K}$. Bulk $a_{\mathrm{w}}$ measurements using the water activity meter in the temperature range from 279 to $298 \mathrm{~K}$ are listed in Table 6 and shown as coloured circles in Fig. 4. Eutectic melting was not observed since the melting point of pure 2-(2-ethoxyethoxy)ethanol $\left(T_{\mathrm{m}}=197 \mathrm{~K}\right)$ is lower than the considered temperature range. The $a_{\mathrm{w}}$ data measured using the water activity meter and DSC data are in good agree-
Table 4. Bulk water activity $\left(a_{\mathrm{W}}\right)$ measurements $*$ of water $(1)+$ 1,4-butanediol (2) solutions at three different temperatures. Solution compositions are given in mole fraction $\left(x_{2}\right)$ of the organic component (2).

\begin{tabular}{cccc}
\hline$x_{2}$ & $\begin{array}{c}a_{\mathrm{W}} \\
(T=289.15 \mathrm{~K})\end{array}$ & $\begin{array}{c}a_{\mathrm{W}} \\
(T=298.15 \mathrm{~K})\end{array}$ & $\begin{array}{c}a_{\mathrm{W}} \\
(T=313.15 \mathrm{~K})\end{array}$ \\
\hline 0.02192 & 0.978 & 0.985 & 0.982 \\
0.04731 & 0.940 & 0.959 & 0.965 \\
0.08020 & 0.918 & 0.935 & 0.958 \\
0.11570 & 0.888 & 0.899 & 0.914 \\
0.16604 & 0.844 & 0.860 & 0.871 \\
0.23358 & 0.787 & 0.808 & 0.816 \\
0.31787 & 0.717 & 0.733 & 0.745 \\
0.44309 & 0.611 & 0.626 & 0.631 \\
0.61890 & 0.424 & 0.445 & 0.450 \\
\hline
\end{tabular}

* The accuracy of the water activity measurements is specified by the manufacturer as \pm 0.015 (absolute range) in $a_{\mathrm{w}}$.

Table 5. Bulk water activity $\left(a_{\mathrm{W}}\right)$ measurements * of water $(1)+$ methoxyacetic acid (2) solutions at three different temperatures. Solution compositions are given in mole fraction $\left(x_{2}\right)$ of the organic component (2).

\begin{tabular}{cccc}
\hline$x_{2}$ & $\begin{array}{c}a_{\mathrm{W}} \\
(T=279.15 \mathrm{~K})\end{array}$ & $\begin{array}{c}a_{\mathrm{W}} \\
(T=289.15 \mathrm{~K})\end{array}$ & $\begin{array}{c}a_{\mathrm{W}} \\
(T=298.15 \mathrm{~K})\end{array}$ \\
\hline 0.02185 & 0.953 & 0.961 & 0.969 \\
0.04762 & 0.947 & 0.934 & 0.958 \\
0.07433 & 0.922 & 0.920 & 0.939 \\
0.11760 & 0.897 & 0.874 & 0.912 \\
0.16659 & 0.866 & 0.844 & 0.880 \\
0.22976 & 0.830 & 0.789 & 0.807 \\
0.31637 & 0.702 & 0.720 & 0.715 \\
0.44445 & 0.555 & 0.560 & 0.564 \\
0.63961 & 0.346 & 0.346 & 0.354 \\
\hline
\end{tabular}

* The accuracy of the water activity measurements is specified by the manufacturer as \pm 0.015 (absolute range) in $a_{\mathrm{w}}$.

ment with the parameterised temperature dependence by Zobrist et al. (2008) - the latter is displayed by the coloured dash-dotted lines. Both the $a_{\mathrm{w}}$ measurements and the parameterisation indicate a decrease in $a_{\mathrm{w}}$ with decrease in temperature. The $a_{\mathrm{w}}$ derived from the total gas phase pressure measurements are in good agreement with the $a_{\mathrm{w}}$ data obtained from the water activity meter and the parameterisation for $T>265 \mathrm{~K}$ and for mass fractions of the organic component, $w_{\text {org }}$, of $60 \mathrm{wt} \% \leq w_{\text {org }} \leq 90 \mathrm{wt} \%$. At lower temperatures, $a_{\mathrm{w}}$ strongly increases with decreasing temperature for $w_{\text {org }} \geq 80 \mathrm{wt} \%$. At $T=225 \mathrm{~K}$, all the solid lines converge. Such a temperature dependence of water activity is expected for solutions that exhibit a phase transition (as seen when the curves bend and follow the melting curves in the previous systems, where two solid phases exist at lower $T$ ). Another possibility for such a convergence would be that a phase transition in terms of a liquid-liquid phase separation occurs at 
Table 6. Bulk water activity $\left(a_{\mathrm{W}}\right)$ measurements * of water $(1)+$ 2-(2-ethoxyethoxy)ethanol (2) solutions at three different temperatures. Solution compositions are given in mole fraction $\left(x_{2}\right)$ of the organic component (2).

\begin{tabular}{cccc}
\hline$x_{2}$ & $\begin{array}{c}a_{\mathrm{W}} \\
(T=279.15 \mathrm{~K})\end{array}$ & $\begin{array}{c}a_{\mathrm{W}} \\
(T=289.15 \mathrm{~K})\end{array}$ & $\begin{array}{c}a_{\mathrm{W}} \\
(T=298.15 \mathrm{~K})\end{array}$ \\
\hline 0.01455 & 0.943 & 0.995 & 0.997 \\
0.03275 & 0.935 & 0.986 & 0.982 \\
0.05434 & 0.916 & 0.978 & 0.975 \\
0.08182 & 0.900 & 0.929 & 0.933 \\
0.11827 & 0.862 & 0.870 & 0.904 \\
0.16747 & 0.822 & 0.839 & 0.866 \\
0.23851 & 0.742 & 0.772 & 0.813 \\
0.28670 & 0.703 & 0.738 & 0.780 \\
0.34830 & 0.645 & 0.690 & 0.711 \\
0.43139 & 0.582 & 0.613 & 0.641 \\
0.54853 & 0.485 & 0.498 & 0.540 \\
0.71022 & 0.328 & 0.333 & 0.367 \\
\hline
\end{tabular}

* The accuracy of the water activity measurements is specified by the manufacturer as \pm 0.015 (absolute range) in $a_{\mathrm{W}}$.

low temperatures. It should be noted that measurement artefacts would not be expected to lead to a convergence of the curves onto the ice melting curve at a common temperature. Complementary measurements using the EDB could not be performed for this system due to the comparably high vapour pressure of 2-(2-ethoxyethoxy)ethanol at room temperature, which leads to fast evaporation during injection of the particle into the EDB. At lower $w_{\text {org }}(10$ to $50 \mathrm{wt} \%)$ the solid coloured lines show good agreement with the parameterisation by Zobrist et al. (2008). The water activity data derived from the total gas phase pressure measurements for various concentrations are provided in Table 14.

\subsection{M5 (multicomponent dicarboxylic acid) mixture}

Figure 5 shows $a_{\mathrm{w}}$ measurements for aqueous solutions of M5 over a concentration range from 10 to 84 wt \% M5 (i.e. up to the solution saturation limit at $298 \mathrm{~K}$ ) in the temperature range from 225 to $313 \mathrm{~K}$. Bulk $a_{\mathrm{w}}$ measurements performed in the temperature range from 279 to $313 \mathrm{~K}$ are represented by the coloured circles and are listed in Table 7 and Table 8 . Humidity cycles of single levitated particles in the EDB were performed in the temperature range from 233 to $289 \mathrm{~K}$ and are represented by filled coloured diamonds. M5 mixture compositions and $a_{\mathrm{w}}$ data for the aqueous solutions are listed in Table 9-11. The total gas phase pressure measurements are represented by solid and dashed lines (dashed for M5 mass fractions from 75 to $84 \mathrm{wt} \%$ ) in Fig. 5. For mass fractions $w_{\mathrm{M} 5}>50 \mathrm{wt} \%$ both EDB measurements and total gas phase pressure measurements show an increase in $a_{\mathrm{w}}$ with decreasing temperature, with a stronger effect at higher concentrations. No simple (pseudo-binary) eutectic melting was observed because in the case of the total gas

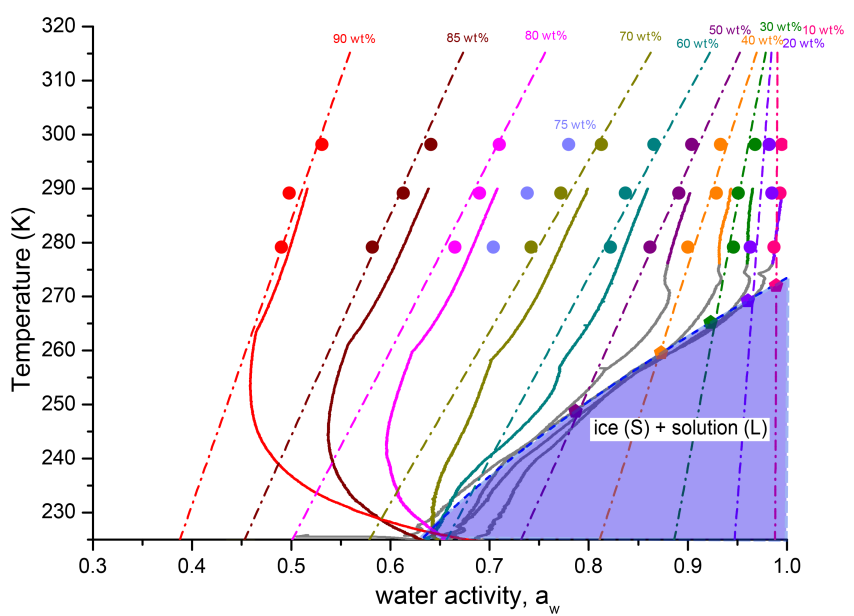

Figure 4. Experimental water activities vs. temperature for aqueous 2-(2-ethoxyethoxy)ethanol solutions. The different colours indicate the solution compositions in wt $\%$ of the organic component. The solid curves show data derived from the total gas phase pressure measurements. The coloured portion of the solid curves represents the temperature range for which the measurements are considered reliable. Water activity data obtained from DSC measurements on the water-ice melting curve from Zobrist et al. (2008) are represented by solid pentagons. The solid circles show the data from bulk $a_{\mathrm{W}}$ measurements with the water activity meter. The dash-dotted lines show the composition- and temperature-dependent $a_{\mathrm{w}}$ parameterisation by Zobrist et al. (2008). The blue dashed line is the ice melting curve (Koop and Zobrist, 2009).

phase pressure measurements individual components of the M5 mixture crystallise at different temperatures and mass fractions of M5. We assume that the total pressure data for $w_{\mathrm{M} 5}>70 \mathrm{wt} \%$ (shown by dashed coloured lines in Fig. 5) are influenced by the crystallisation of certain components of the M5 mixture. These data are not considered to reflect the water activity of the initial mixtures and are therefore not tabulated. The same might be true for the bulk $a_{\mathrm{w}}$ data points at $279 \mathrm{~K}$ and concentrations of $80 \mathrm{wt} \%$, which might explain their high water activity. Table 15 provides the composition of the M5 + water mixtures used for the total gas phase pressure measurements; corresponding water activities are listed in Table 16. Thus it should be noted that both M5 and 2(2-ethoxyethoxy)ethanol solutions show a similar effect of increase in $a_{\mathrm{w}}$ with decrease in temperature at higher concentrations.

\section{Discussion}

\subsection{Measurement techniques: scope and limitations}

Water activity as a function of solute concentration can be measured either for bulk solutions or by single-particle measurement techniques. To measure $a_{\mathrm{w}}$ of bulk solutions, commercial dew point water activity meters are probably the best 
Table 7. Bulk water activity $\left(a_{\mathrm{W}}\right)$ measurements* of aqueous M5 solutions at 289.15, 298.15 and $313.15 \mathrm{~K}$. The total organic mass fraction of the solution is given in the first column in wt \% and the composition in terms of individual components is given in mole fractions of the dicarboxylic acids constituting the M5 mixture.

\begin{tabular}{ccccccccc}
\hline $\mathrm{wt} \%$ & $x$ (DL-malic) & $x$ (malonic) & $x$ (maleic) & $x$ (glutaric) & $x$ (methylsuccinic) & $a_{\mathrm{w}}(289.15)$ & $a_{\mathrm{w}}(298.15)$ & $a_{\mathrm{w}}(313.15)$ \\
\hline 10.01 & 0.00247 & 0.00537 & 0.00193 & 0.00450 & 0.00200 & 0.984 & 0.991 & 0.989 \\
20.01 & 0.00545 & 0.01184 & 0.00423 & 0.00991 & 0.00441 & 0.966 & 0.974 & 0.977 \\
30.01 & 0.00908 & 0.01978 & 0.00711 & 0.01659 & 0.00735 & 0.945 & 0.951 & 0.960 \\
39.68 & 0.01370 & 0.02852 & 0.01065 & 0.02492 & 0.01106 & 0.917 & 0.922 & 0.930 \\
49.97 & 0.01962 & 0.04270 & 0.01528 & 0.03577 & 0.01587 & 0.873 & 0.877 & 0.880 \\
54.99 & 0.02332 & 0.05074 & 0.01819 & 0.04251 & 0.01889 & 0.844 & 0.853 & 0.860 \\
60.01 & 0.02766 & 0.06021 & 0.02157 & 0.05043 & 0.02241 & 0.804 & 0.807 & 0.807 \\
69.98 & 0.03904 & 0.08503 & 0.03042 & 0.07120 & 0.03158 & 0.694 & 0.700 & 0.702 \\
79.87 & 0.05631 & 0.12246 & 0.04385 & 0.10263 & 0.04556 & 0.542 & 0.543 & 0.543 \\
84.41 & 0.06768 & 0.14725 & 0.05279 & 0.12339 & 0.05478 & 0.450 & 0.447 & 0.458 \\
\hline
\end{tabular}

* The accuracy of the water activity measurements is specified by the manufacturer as \pm 0.003 (absolute range) in $a_{\mathrm{w}}$.

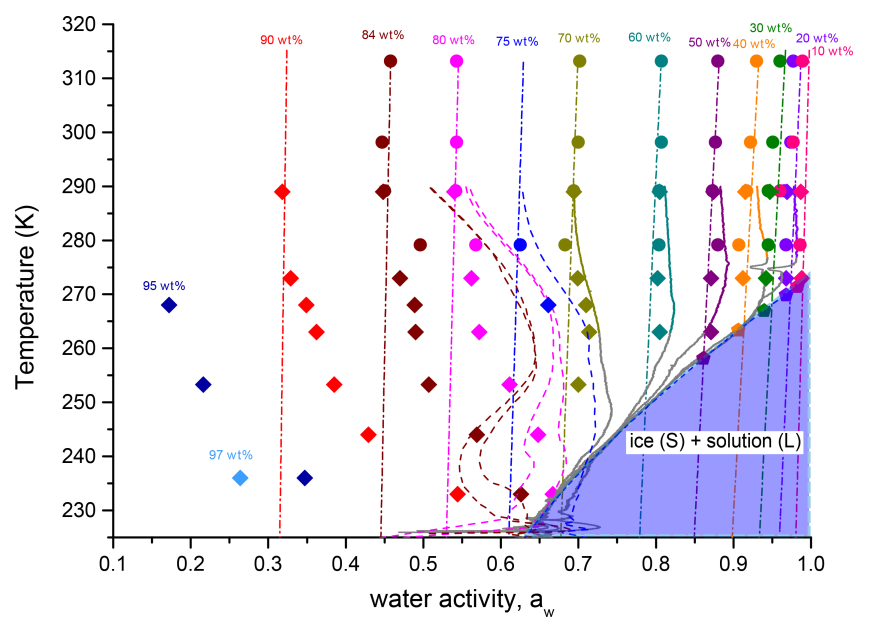

Figure 5. Experimental water activities vs. temperature for aqueous M5 solutions. The solid and dashed curves are from the total gas phase pressure measurements. The coloured dashed curves (75$84 \mathrm{wt} \%$ ) represent measurements for which the solution was not in a homogeneous liquid state but partly crystallised. The coloured portion of the solid curves represents the temperature range for which the measurements are considered reliable (grey elsewhere). Water activity data obtained from DSC measurements on the waterice melting curve from Zobrist et al. (2008) are shown by solid pentagons. The solid circles show the data from bulk $a_{\mathrm{w}}$ measurements with the water activity meter. The dash-dotted lines show the composition- and temperature-dependent $a_{\mathrm{w}}$ parameterisation by Zobrist et al. (2008). The blue dashed line is the ice melting curve (Koop and Zobrist, 2009). The $a_{\mathrm{w}}$ data from EDB measurements are represented by coloured diamonds.

choice because they have high accuracy and cover a wide concentration range, thus providing $a_{\mathrm{w}}$ data from saturated to dilute solutions. However, their accuracy decreases for water activities close to 1 . Therefore they are less suited for very dilute solutions. Moreover, the commercially available water activity meters typically provide data for temperatures $>273 \mathrm{~K}$ and experiments are time consuming when point-topoint measurements have to be performed over a wide temperature range.

The DSC technique provides accurate measurements of solid-liquid equilibrium curves. DSC measurements are performed at fixed composition and can provide $T_{\mathrm{m}}, T_{\mathrm{hom}}$ and glass transition temperatures $\left(T_{\mathrm{g}}\right)$ of aqueous solutions. From the melting point depression of ice in aqueous solutions, accurate values of $a_{\mathrm{w}}$ on the SLE phase boundary of the aqueous solution and ice can be obtained, because the vapour pressures of ice and water at atmospheric temperatures are well known (see Sect. 2.1). When oil-in-water emulsions instead of bulk samples are measured, homogeneous freezing temperatures $T_{\text {hom }}$ can also be obtained. This is especially useful because homogeneous ice nucleation temperatures of aqueous solutions can be parameterised in terms of water activity following Koop et al. (2000) and Koop and Zobrist (2009). The drawback of the DSC technique is that only $a_{\mathrm{w}}$ data on the ice melting curve, thus over a limited range of compositions, are obtained.

Electrodynamic balance and optical tweezers in addition offer a possibility to measure the water activity via the mass or size change of hygroscopic, micrometre-sized particles (Krieger et al., 2012). In both techniques, the particles are levitated without contact to any surface. Hence the supersaturated concentration range can be investigated when the particles are exposed to humidity cycles. In the absence of liquid/gas phase diffusion limitations and given the relatively large diameters of solution droplets (Kelvin effect can be ignored), the RH of the gas phase corresponds with $a_{\mathrm{w}}$ of the condensed phase. Thus, the water content of the levitated particle in terms of a mass or molar fraction can be calculated from the mass data when the dry particle mass is known. The more accurate radius data obtained from the Mie scattering pattern of an illuminating light beam can be used to derive mass or mole fractions of solute but need refractive 
Table 8. Bulk water activity $\left(a_{\mathrm{w}}\right)$ measurements* of aqueous M5 solutions at $279.15 \mathrm{~K}$. The total organic fraction of the solution is given in the first column in wt\% and the composition in terms of individual components is given in mole fractions of the dicarboxylic acids constituting the M5 mixture.

\begin{tabular}{ccccccc}
\hline wt $\%$ & $x$ (DL-malic) & $x$ (malonic) & $x$ (maleic) & $x$ (glutaric) & $x$ (methylsuccinic) & $a_{\mathrm{w}}$ \\
\hline 10.04 & 0.00339 & 0.00602 & 0.00335 & 0.00259 & 0.00112 & 0.986 \\
20.09 & 0.00768 & 0.00794 & 0.00921 & 0.00824 & 0.00248 & 0.968 \\
30.05 & 0.01262 & 0.01436 & 0.01509 & 0.01368 & 0.00386 & 0.945 \\
40.10 & 0.01910 & 0.03182 & 0.01385 & 0.02043 & 0.00556 & 0.907 \\
50.07 & 0.02461 & 0.04022 & 0.02371 & 0.03281 & 0.00792 & 0.880 \\
60.09 & 0.03001 & 0.04019 & 0.04088 & 0.05020 & 0.01840 & 0.804 \\
70.21 & 0.04604 & 0.07285 & 0.06374 & 0.05439 & 0.02133 & 0.683 \\
75.06 & 0.05403 & 0.08763 & 0.06039 & 0.06100 & 0.04357 & 0.625 \\
80.07 & 0.06972 & 0.08695 & 0.08148 & 0.07131 & 0.05207 & 0.568 \\
\hline
\end{tabular}

* The accuracy of the water activity measurements is specified by the manufacturer as \pm 0.003 (absolute range) in $a_{\mathrm{W}}$.

Table 9. EDB measurements: the total organic fraction of the solution is given in the first column in wt $\%$ and the composition in terms of individual components is given in mole fractions of the dicarboxylic acids constituting the M5 mixture.

\begin{tabular}{cccccc}
\hline wt $\%$ & $x$ (DL-malic) & $x$ (malonic) & $x$ (maleic) & $x$ (glutaric) & $x$ (methylsuccinic) \\
\hline 10.01 & 0.00247 & 0.00537 & 0.00193 & 0.00450 & 0.00200 \\
20.01 & 0.00545 & 0.01184 & 0.00423 & 0.00991 & 0.00441 \\
30.01 & 0.00908 & 0.01978 & 0.00711 & 0.01659 & 0.00735 \\
39.68 & 0.01370 & 0.02852 & 0.01065 & 0.02492 & 0.01106 \\
49.97 & 0.01962 & 0.04270 & 0.01528 & 0.03577 & 0.01587 \\
54.99 & 0.02332 & 0.05074 & 0.01819 & 0.04251 & 0.01889 \\
60.01 & 0.02766 & 0.06021 & 0.02157 & 0.05043 & 0.02241 \\
69.98 & 0.03904 & 0.08503 & 0.03042 & 0.07120 & 0.03158 \\
79.87 & 0.05631 & 0.12246 & 0.04385 & 0.10263 & 0.04556 \\
84.41 & 0.06768 & 0.14725 & 0.05279 & 0.12339 & 0.05478 \\
\hline
\end{tabular}

Table 10. Water activity $\left(a_{\mathrm{W}}\right)$ measurements * of aqueous M5 solutions from EDB hygroscopic growth curves evaluated at the indicated weight fractions. The corresponding M5 solution compositions in terms of organic components are given in Table 9.

\begin{tabular}{cccccc}
\hline wt \% & $a_{\mathrm{w}}$ & $a_{\mathrm{W}}$ & $a_{\mathrm{w}}$ & $a_{\mathrm{w}}$ & $a_{\mathrm{W}}$ \\
& $(289 \mathrm{~K})$ & $(273 \mathrm{~K})$ & $(263 \mathrm{~K})$ & $(244 \mathrm{~K})$ & $(233 \mathrm{~K})$ \\
\hline 10.01 & 0.987 & & & & \\
20.01 & 0.969 & & & & \\
30.01 & 0.947 & & & & \\
39.68 & 0.915 & & & & \\
49.97 & 0.874 & 0.867 & & & \\
54.99 & 0.839 & 0.839 & 0.841 & & \\
60.01 & 0.805 & 0.802 & 0.805 & & \\
69.98 & 0.694 & 0.699 & 0.714 & & \\
79.87 & 0.540 & 0.562 & 0.572 & 0.648 & 0.667 \\
84.41 & 0.448 & 0.470 & 0.490 & 0.569 & 0.626 \\
90.00 & 0.318 & 0.329 & 0.362 & 0.429 & 0.544 \\
\hline
\end{tabular}

* The accuracy of the water activity measurements is specified as \pm 0.015 (absolute range) in $a_{\mathrm{w}}$ and $\leq 0.1 \mathrm{~K}$ in temperature.
Table 11. Water activity $\left(a_{\mathrm{W}}\right)$ measurements * of aqueous M5 solutions from EDB hygroscopic growth curves evaluated at the indicated weight fractions.

\begin{tabular}{cccc}
\hline wt \% & $\begin{array}{c}a_{\mathrm{w}} \\
(268 \mathrm{~K})\end{array}$ & $\begin{array}{c}a_{\mathrm{w}} \\
(253 \mathrm{~K})\end{array}$ & $\begin{array}{c}a_{\mathrm{W}} \\
(236 \mathrm{~K})\end{array}$ \\
\hline 60.00 & 0.791 & & \\
65.00 & 0.767 & & \\
70.00 & 0.725 & & \\
73.00 & & 0.700 & \\
75.00 & 0.676 & & \\
80.00 & 0.602 & 0.611 & \\
85.00 & 0.504 & 0.507 & \\
90.00 & 0.364 & 0.385 & \\
95.60 & 0.172 & 0.216 & 0.347 \\
97.20 & & & 0.264
\end{tabular}

* The accuracy of the water activity measurements is specified as \pm 0.015 (absolute range) in $a_{\mathrm{W}}$ and $\leq 0.1 \mathrm{~K}$ in temperature 
Table 12. Measured water activities of water (1) + 1,4butanediol (2) mixtures derived from total gas phase pressure measurements*, listed for a selection of temperatures in the range $270 \mathrm{~K}<T<291 \mathrm{~K}$. Solution compositions are given in mole fractions of the organic $\left(x_{2}\right)$.

\begin{tabular}{|c|c|c|c|c|c|}
\hline$x_{2}$ & $\begin{array}{c}a_{\mathrm{W}} \\
(270.15 \mathrm{~K})\end{array}$ & $x_{2}$ & $\begin{array}{c}a_{\mathrm{W}} \\
(273.15 \mathrm{~K})\end{array}$ & $x_{2}$ & $\begin{array}{c}a_{\mathrm{W}} \\
(275.15 \mathrm{~K})\end{array}$ \\
\hline 0.24441 & 0.762 & 0.24441 & 0.766 & 0.23200 & 0.812 \\
\hline 0.26933 & 0.751 & 0.26933 & 0.754 & 0.24441 & 0.768 \\
\hline 0.31705 & 0.688 & 0.31705 & 0.694 & 0.26933 & 0.755 \\
\hline 0.37368 & 0.654 & 0.37368 & 0.658 & 0.31705 & 0.697 \\
\hline \multirow[t]{3}{*}{0.44332} & 0.604 & 0.44332 & 0.606 & 0.37368 & 0.660 \\
\hline & & 0.52556 & 0.502 & 0.44332 & 0.607 \\
\hline & & & & 0.52556 & 0.504 \\
\hline$x_{2}$ & $\begin{array}{c}a_{\mathrm{W}} \\
(278.15 \mathrm{~K})\end{array}$ & $x_{2}$ & $\begin{array}{c}a_{\mathrm{W}} \\
(280.15 \mathrm{~K})\end{array}$ & $x_{2}$ & $\begin{array}{c}a_{\mathrm{W}} \\
(283.15 \mathrm{~K})\end{array}$ \\
\hline 0.24441 & 0.772 & 0.04797 & 0.971 & 0.04797 & 0.971 \\
\hline 0.26933 & 0.757 & 0.11823 & 0.900 & 0.11823 & 0.901 \\
\hline 0.31705 & 0.702 & 0.16701 & 0.868 & 0.16701 & 0.868 \\
\hline 0.37368 & 0.663 & 0.23200 & 0.813 & 0.23200 & 0.813 \\
\hline 0.44332 & 0.608 & 0.24441 & 0.775 & 0.24441 & 0.776 \\
\hline 0.52556 & 0.507 & 0.26933 & 0.759 & 0.26933 & 0.761 \\
\hline \multirow[t]{5}{*}{0.64080} & 0.396 & 0.31705 & 0.706 & 0.31705 & 0.710 \\
\hline & & 0.37368 & 0.665 & 0.37368 & 0.667 \\
\hline & & 0.44332 & 0.608 & 0.44332 & 0.610 \\
\hline & & 0.52556 & 0.508 & 0.52556 & 0.510 \\
\hline & & 0.64080 & 0.399 & 0.64080 & 0.402 \\
\hline$x_{2}$ & $\begin{array}{c}a_{\mathrm{W}} \\
(285.15 \mathrm{~K})\end{array}$ & $x_{2}$ & $\begin{array}{c}a_{\mathrm{W}} \\
(288.15 \mathrm{~K})\end{array}$ & $x_{2}$ & $\begin{array}{c}a_{\mathrm{W}} \\
(290.15 \mathrm{~K})\end{array}$ \\
\hline 0.04797 & 0.969 & 0.04797 & 0.967 & 0.04797 & 0.969 \\
\hline 0.11823 & 0.901 & 0.11823 & 0.901 & 0.11823 & 0.906 \\
\hline 0.16701 & 0.869 & 0.16701 & 0.868 & 0.16701 & 0.873 \\
\hline 0.23200 & 0.814 & 0.23200 & 0.815 & 0.23200 & 0.818 \\
\hline 0.24441 & 0.778 & 0.24441 & 0.780 & 0.24441 & 0.786 \\
\hline 0.26933 & 0.763 & 0.26933 & 0.766 & 0.26933 & 0.770 \\
\hline 0.31705 & 0.712 & 0.31705 & 0.716 & 0.31705 & 0.724 \\
\hline 0.37368 & 0.667 & 0.37368 & 0.669 & 0.37368 & 0.673 \\
\hline 0.44332 & 0.611 & 0.44332 & 0.611 & 0.44332 & 0.615 \\
\hline 0.52556 & 0.512 & 0.52556 & 0.513 & 0.52556 & 0.517 \\
\hline 0.64080 & 0.403 & 0.64080 & 0.404 & 0.64080 & 0.406 \\
\hline
\end{tabular}

* The accuracy of the water activity measurements is \pm 0.03 (absolute range) in $a_{\mathrm{w}}$.

index data and density data for the measurement evaluation. The available temperature range depends on the cooling and heating possibilities of the specific setup. Since the particles are airborne without contact to any surface (walls), $a_{\mathrm{w}}$ of highly supersaturated solutions can be obtained, covering thus a concentration range that is not accessible by standard bulk methods. The applicability of single-particle techniques for water activity measurements is limited by the volatility of the substances under investigation. The range of substances that may be investigated is enlarged at low temperature since vapour pressure strongly decreases with decreasing temperature. To take full advantage of this, injection of particles should occur at the measurement temperature to avoid complete evaporation before the measurement temperature is reached.
Total gas phase pressure measurements over aqueous solutions can provide water activities when the measured total pressure can be completely ascribed to water vapour. Since this technique needs bulk volumes, $a_{\mathrm{w}}$ data can be obtained from dilute up to saturated solutions. When the sample is kept in an externally regulated thermostat, temperature profiles can be run that provide water activity data of solutions at fixed concentration covering a wide temperature range. Apart from deriving $a_{\mathrm{w}}$ from the measured data, the total gas phase pressure measurements can also provide information about eutectic melting points and solid-liquid equilibria. However, accurate measurements of water activities rely on efficient removal of the residual gases from the solution to make sure that the measured total pressure corresponds to the water vapour pressure over the solution. Great care needs to be taken during the removal of residual gases since there is always the danger of overpumping which may change the concentration of the solution (removal of significant amounts of water). The total gas phase pressure measurements are also prone to artefacts. The freezing/thawing process can lead to composition heterogeneity in the sample. Some solutions show a strong foaming during melting leading to tiny droplets settling on the walls of the solution flask. These drops can influence the gas phase pressure when they are at a higher temperature than the bulk solution or when they are of a different composition due to arising heterogeneity during the freezing and thawing processes. To cover a large concentration and temperature range, organic substances with a low melting point and a high water solubility are required. These conditions strongly reduce the number of compounds for which total gas phase pressure measurements may provide a large extension to composition/temperature ranges that are not covered by other methods. These drawbacks together with the rather difficult handling of the instrumental setup render total gas phase pressure measurements to be less attractive than the alternative techniques such as DSC and EDB measurements. A good temperature and concentration coverage can be achieved when $a_{\mathrm{w}}$ bulk measurements are combined with EDB experiments.

\subsection{Hydrogen bonding effects on water activity in aqueous solutions}

This section is intended to interpret the strong change of water activity with decreasing temperature observed for some investigated substances. In this context we discuss changes in hydrogen bonding, which play an important role. Hydrogen bonding increases with decreasing temperature and might become more influential at low temperature. Hydrogen bonds are strong electrostatic dipole-dipole interactions that occur between covalently bound hydrogen atoms and the free electron pair of a highly electronegative atom, such as nitrogen $(\mathrm{N})$, oxygen $(\mathrm{O})$ or fluorine $(\mathrm{F})$. They have some features of covalent bonding since they are directional and can lead to interatomic distances shorter than the sum of the van der 
Table 13. Measured water activities of water (1)+ methoxyacetic acid (2) mixtures derived from total gas phase pressure measurements*, listed for a selection of temperatures in the range $268 \mathrm{~K}<T<291 \mathrm{~K}$. Solution compositions are given in mole fractions of the organic $\left(x_{2}\right)$.

\begin{tabular}{|c|c|c|c|c|c|c|c|}
\hline$x_{2}$ & $a_{\mathrm{W}}(268.15 \mathrm{~K})$ & $x_{2}$ & $a_{\mathrm{W}}(270.15 \mathrm{~K})$ & $x_{2}$ & $a_{\mathrm{W}}(273.15 \mathrm{~K})$ & $x_{2}$ & $a_{\mathrm{W}}(275.15 \mathrm{~K})$ \\
\hline 0.43712 & 0.607 & 0.31301 & 0.750 & 0.31301 & 0.749 & 0.22937 & 0.835 \\
\hline 0.53152 & 0.509 & 0.43712 & 0.608 & 0.43712 & 0.608 & 0.31301 & 0.749 \\
\hline \multirow[t]{3}{*}{0.63995} & 0.328 & 0.53152 & 0.510 & 0.53152 & 0.511 & 0.43712 & 0.608 \\
\hline & & 0.63995 & 0.331 & 0.63995 & 0.336 & 0.53152 & 0.511 \\
\hline & & & & & & 0.63995 & 0.337 \\
\hline$x_{2}$ & $a_{\mathrm{W}}(278.15 \mathrm{~K})$ & $x_{2}$ & $a_{\mathrm{W}}(280.15 \mathrm{~K})$ & $x_{2}$ & $a_{\mathrm{W}}(283.15 \mathrm{~K})$ & $x_{2}$ & $a_{\mathrm{W}}(285.15 \mathrm{~K})$ \\
\hline 0.02180 & 0.983 & 0.02180 & 0.983 & 0.02180 & 0.983 & 0.02180 & 0.983 \\
\hline 0.04757 & 0.974 & 0.04757 & 0.974 & 0.04757 & 0.975 & 0.04757 & 0.975 \\
\hline 0.07904 & 0.960 & 0.07904 & 0.958 & 0.07904 & 0.954 & 0.07904 & 0.952 \\
\hline 0.11765 & 0.924 & 0.11765 & 0.921 & 0.11765 & 0.918 & 0.11765 & 0.916 \\
\hline 0.16696 & 0.893 & 0.16696 & 0.888 & 0.16696 & 0.885 & 0.16696 & 0.884 \\
\hline 0.22937 & 0.832 & 0.22937 & 0.831 & 0.22937 & 0.830 & 0.22937 & 0.829 \\
\hline 0.31301 & 0.748 & 0.31301 & 0.748 & 0.31301 & 0.747 & 0.31301 & 0.747 \\
\hline 0.43712 & 0.607 & 0.43712 & 0.605 & 0.43712 & 0.604 & 0.43712 & 0.603 \\
\hline 0.53152 & 0.511 & 0.53152 & 0.510 & 0.53152 & 0.509 & 0.53152 & 0.509 \\
\hline 0.63995 & 0.340 & 0.63995 & 0.341 & 0.63995 & 0.343 & 0.63995 & 0.344 \\
\hline$x_{2}$ & $a_{\mathrm{W}}(288.15 \mathrm{~K})$ & $x_{2}$ & $a_{\mathrm{W}}(290.15 \mathrm{~K})$ & & & & \\
\hline 0.02180 & 0.983 & 0.02180 & 0.987 & & & & \\
\hline 0.04757 & 0.976 & 0.04757 & 0.980 & & & & \\
\hline 0.07904 & 0.946 & 0.07904 & 0.949 & & & & \\
\hline 0.11765 & 0.915 & 0.11765 & 0.918 & & & & \\
\hline 0.16696 & 0.882 & 0.16696 & 0.884 & & & & \\
\hline 0.22937 & 0.829 & 0.22937 & 0.830 & & & & \\
\hline 0.31301 & 0.745 & 0.31301 & 0.747 & & & & \\
\hline 0.43712 & 0.601 & 0.43712 & 0.602 & & & & \\
\hline 0.53152 & 0.507 & 0.53152 & 0.508 & & & & \\
\hline 0.63995 & 0.346 & 0.63995 & 0.348 & & & & \\
\hline
\end{tabular}

* The accuracy of the water activity measurements is \pm 0.03 (absolute range) in $a_{\mathrm{W}}$.

Waals radii of the involved atoms. Hydrogen bonds have a strong influence on the activity of the constituents in a solution. In aqueous solutions of alcohols and organic acids, organic-organic, organic-water, and water-water hydrogen bonds can form. In general, organic-water hydrogen bonds decrease $a_{\mathrm{w}}$ while association of organic molecules among each other leads to an increase in water activity. The strength and average number of hydrogen bonds per molecule depends on concentration and temperature. A strong increase of $a_{\mathrm{w}}$ with decreasing temperature can be rationalised in terms of association of solute molecules among each other. Therefore, the analysis of the hydrogen bonds present in aqueous solutions can help to understand the temperature dependence of water activity.

The carboxyl group of organic acids can build hydrogen bonds with water or other dicarboxylic acids. The hydrogen atoms of the carboxyl group form hydrogen bonds with the free electron pair of the oxygen atoms of a carboxyl group of another acid molecule. Similarly, for dicarboxylic acids when the hydrogen bonds connect to another dicarboxylic acid molecule this leads to an association of dicarboxylic acids and formation of a dimer, which reduces the effective number of dissolved species and leads to a relative increase in water activity. Hydrogen bonds between water and dicarboxylic acids lead to a relative decrease of water activity.

Aqueous solutions of poly(ethylene glycol) (PEG) have attracted much attention because of their extraordinary mixing behaviour with water and their importance in pharmaceutical and biomedical appliances (Dormidontova, 2002). 2-(2-ethoxyethoxy)ethanol shares with PEG the $-\mathrm{CH}_{2}-\mathrm{CH}_{2}-\mathrm{O}-$ repetition unit as the main structural feature. Different from PEG with two terminal hydroxyl groups, 2-(2-ethoxyethoxy)ethanol carries one terminal methyl and one terminal hydroxyl group, which makes it less hydrophilic. The $-\mathrm{CH}_{2}-\mathrm{CH}_{2}-\mathrm{O}-$ repetition unit lends 2-(2ethoxyethoxy)ethanol and PEG a higher solubility than typical for ethers. This behaviour can be rationalised by the increased structuring of water around PEG molecules. This structuring is a consequence of hydrogen bonding and the ability of the PEG structure to fill out the natural cavities in 
Table 14. Measured water activities of water (1) + 2-(2-ethoxyethoxy)ethanol (2) mixtures derived from total gas phase pressure measurements*, listed for a selection of temperatures in the range $265 \mathrm{~K}<T<291 \mathrm{~K}$. Solution compositions are given in mole fractions of the organic $\left(x_{2}\right)$.

\begin{tabular}{|c|c|c|c|c|c|c|c|}
\hline$x_{2}$ & $a_{\mathrm{W}}(265.15 \mathrm{~K})$ & $x_{2}$ & $a_{\mathrm{W}}(268.15 \mathrm{~K})$ & $x_{2}$ & $a_{\mathrm{W}}(270.15 \mathrm{~K})$ & $x_{2}$ & $a_{\mathrm{W}}(273.15 \mathrm{~K})$ \\
\hline 0.54409 & 0.469 & 0.54409 & 0.477 & 0.54409 & 0.481 & 0.54409 & 0.488 \\
\hline 0.42719 & 0.573 & 0.42719 & 0.583 & 0.42719 & 0.589 & 0.42719 & 0.598 \\
\hline 0.34418 & 0.644 & 0.34418 & 0.654 & 0.34418 & 0.660 & 0.34418 & 0.669 \\
\hline 0.23774 & 0.732 & 0.23774 & 0.742 & 0.23774 & 0.748 & 0.23774 & 0.756 \\
\hline 0.16753 & 0.801 & 0.16753 & 0.811 & 0.16753 & 0.817 & 0.16753 & 0.824 \\
\hline$x_{2}$ & $a_{\mathrm{W}}(275.15 \mathrm{~K})$ & $x_{2}$ & $a_{\mathrm{W}}(278.15 \mathrm{~K})$ & $x_{2}$ & $a_{\mathrm{W}}(280.15 \mathrm{~K})$ & $x_{2}$ & $a_{\mathrm{W}}(283.15 \mathrm{~K})$ \\
\hline 0.54409 & 0.492 & 0.54409 & 0.497 & 0.54409 & 0.501 & 0.54409 & 0.506 \\
\hline 0.42719 & 0.603 & 0.42719 & 0.610 & 0.42719 & 0.616 & 0.42719 & 0.622 \\
\hline 0.34418 & 0.674 & 0.34418 & 0.681 & 0.34418 & 0.685 & 0.34418 & 0.692 \\
\hline 0.23774 & 0.762 & 0.23774 & 0.769 & 0.23774 & 0.774 & 0.23774 & 0.782 \\
\hline 0.16753 & 0.828 & 0.16753 & 0.835 & 0.16753 & 0.839 & 0.16753 & 0.845 \\
\hline \multirow[t]{4}{*}{0.11810} & 0.878 & 0.11810 & 0.883 & 0.11810 & 0.886 & 0.11810 & 0.891 \\
\hline & & 0.08217 & 0.932 & 0.08217 & 0.932 & 0.08217 & 0.935 \\
\hline & & 0.05412 & 0.961 & 0.05412 & 0.961 & 0.05412 & 0.961 \\
\hline & & 0.03245 & 0.988 & 0.03245 & 0.989 & 0.03245 & 0.990 \\
\hline$x_{2}$ & $a_{\mathrm{W}}(285.15 \mathrm{~K})$ & $x_{2}$ & $a_{\mathrm{W}}(288.15 \mathrm{~K})$ & $x_{2}$ & $a_{\mathrm{W}}(290.15 \mathrm{~K})$ & & \\
\hline 0.54409 & 0.509 & 0.54409 & 0.514 & 0.54409 & 0.518 & & \\
\hline 0.42719 & 0.627 & 0.42719 & 0.634 & 0.42719 & 0.643 & & \\
\hline 0.34418 & 0.696 & 0.34418 & 0.704 & 0.34418 & 0.711 & & \\
\hline 0.23774 & 0.787 & 0.23774 & 0.795 & 0.23774 & 0.815 & & \\
\hline 0.16753 & 0.849 & 0.16753 & 0.855 & 0.16753 & 0.864 & & \\
\hline 0.11810 & 0.895 & 0.11810 & 0.900 & 0.11810 & 0.907 & & \\
\hline 0.08217 & 0.938 & 0.08217 & 0.941 & 0.08217 & 0.946 & & \\
\hline 0.05412 & 0.962 & 0.05412 & 0.964 & 0.05412 & 0.967 & & \\
\hline 0.03245 & 0.992 & 0.03245 & 0.994 & 0.03245 & 0.998 & & \\
\hline
\end{tabular}

* The accuracy of the water activity measurements is \pm 0.03 (absolute range) in $a_{\mathrm{W}}$.

Table 15. Mixture compositions at different overall organic mass fractions of the aqueous M5 system used for total gas phase pressure measurements. Component mole fractions $(x)$ of the dicarboxylic acids constituting the M5 mixture are given, with water accounting for the remaining fraction.

\begin{tabular}{cccccc}
\hline wt $\%$ & $x$ (DL-malic acid $)$ & $x$ (malonic acid $)$ & $x$ (maleic acid $)$ & $x$ (glutaric acid $)$ & $x$ (methylsuccinic acid) \\
\hline 20 & 0.00545 & 0.01183 & 0.00428 & 0.00992 & 0.00441 \\
40 & 0.01353 & 0.02815 & 0.01064 & 0.02453 & 0.01085 \\
50 & 0.01959 & 0.04236 & 0.01526 & 0.03581 & 0.01672 \\
60 & 0.02746 & 0.06049 & 0.02135 & 0.04971 & 0.02241 \\
70 & 0.03833 & 0.08327 & 0.02997 & 0.06984 & 0.03090 \\
75 & 0.04547 & 0.09924 & 0.03549 & 0.08310 & 0.03700 \\
\hline
\end{tabular}

the hydrogen-bonded network of water. The increased structuring of the water is reflected in the large negative excess entropy of the solution, while its large positive excess heat capacity is due to the temperature sensitivity of the structure (Kjellander and Florin, 1981). This interplay of entropic and enthalpy contributions to the Gibbs energy leads to a closed-loop miscibility gap at elevated temperature (353.15$523.15 \mathrm{~K}$ ) for aqueous PEG solutions with PEG molecular weights of $2200 \mathrm{~g} \mathrm{~mol}^{-1}$ and higher (e.g. Dormidontova, 2004; Kjellander and Florin, 1981; Zobrist et al., 2003).

PEG with molecular weight below $2000 \mathrm{~g} \mathrm{~mol}^{-1}$ do not show liquid-liquid phase separation close to room temperature. However liquid-liquid equilibria are observed for aqueous triethylene glycol solutions (Salabat, 2010) and smaller poly(ethylene glycols) when a salt is added (e.g. Marcolli and Krieger, 2006; Ciobanu et al., 2009). Liquidliquid phase separation below room temperature is not easily 
Table 16. Measured water activities of water (1) + M5 (2) mixtures derived from total gas phase pressure measurements*, listed for a selection of temperatures in the range $265 \mathrm{~K}<T<291 \mathrm{~K}$. The total organic mass fraction of the solution is given in the first column.

\begin{tabular}{|c|c|c|c|c|}
\hline wt $\%$ & $\begin{array}{c}a_{\mathrm{W}} \\
(265.15 \mathrm{~K})\end{array}$ & $\begin{array}{c}a_{\mathrm{W}} \\
(268.15 \mathrm{~K})\end{array}$ & $\begin{array}{c}a_{\mathrm{W}} \\
(270.15 \mathrm{~K})\end{array}$ & $\begin{array}{c}a_{\mathrm{W}} \\
(273.15 \mathrm{~K})\end{array}$ \\
\hline \multicolumn{5}{|l|}{20} \\
\hline 40 & & & & \\
\hline 50 & 0.872 & 0.881 & 0.886 & 0.890 \\
\hline 60 & 0.822 & 0.823 & 0.820 & 0.819 \\
\hline 70 & 0.724 & 0.719 & 0.719 & 0.709 \\
\hline wt $\%$ & $\begin{array}{c}a_{\mathrm{W}} \\
(275.15 \mathrm{~K})\end{array}$ & $\begin{array}{c}a_{\mathrm{W}} \\
(278.15 \mathrm{~K})\end{array}$ & $\begin{array}{c}a_{\mathrm{W}} \\
(280.15 \mathrm{~K})\end{array}$ & $\begin{array}{c}a_{\mathrm{W}} \\
(283.15 \mathrm{~K})\end{array}$ \\
\hline 20 & & 0.982 & 0.982 & 0.981 \\
\hline 40 & & 0.943 & 0.939 & 0.934 \\
\hline 50 & 0.892 & 0.890 & 0.888 & 0.887 \\
\hline 60 & 0.817 & 0.817 & 0.817 & 0.815 \\
\hline 70 & 0.706 & 0.701 & 0.699 & 0.696 \\
\hline wt $\%$ & $\begin{array}{c}a_{\mathrm{W}} \\
(285.15 \mathrm{~K})\end{array}$ & $\begin{array}{c}a_{\mathrm{W}} \\
(288.15 \mathrm{~K})\end{array}$ & $\begin{array}{c}a_{\mathrm{W}} \\
(290.15 \mathrm{~K})\end{array}$ & \\
\hline 20 & 0.980 & 0.980 & 0.982 & \\
\hline 40 & 0.933 & 0.932 & 0.934 & \\
\hline 50 & 0.886 & 0.884 & 0.934 & \\
\hline 60 & 0.814 & 0.812 & 0.826 & \\
\hline 70 & 0.695 & 0.695 & 0.701 & \\
\hline
\end{tabular}

* The accuracy of the water activity measurements is \pm 0.03 (absolute range) in $a_{\mathrm{W}}$.

accessible because of the competition with crystallisation of either the PEG, the ice phase or both phases, depending on solution composition and temperature. Ciobanu et al. (2009) have investigated in detail liquid-liquid phase separation of aqueous PEG-400 solutions when ammonium sulfate is added as a salting-out agent. This phase separation seems to persist or even grow with decreasing temperature. At the onset of liquid-liquid phase separation water activity lines of different concentration converge at a high $a_{\mathrm{w}}$ value. Therefore the strong increase of $a_{\mathrm{w}}$ with decreasing temperature in aqueous M5 and 2-(2-ethoxyethoxy)ethanol solutions may be rationalised in terms of approaching a lowtemperature miscibility gap that is not experimentally accessible because it falls in the concentration/temperature range where ice forms. Low-temperature liquid-liquid transitions without macroscopic phase separation have been observed in different water-sugar and water-polyol systems (Murata and Tanaka, 2013).

\subsection{Atmospheric implications}

In the upper troposphere, one pathway for cirrus cloud formation is by means of homogeneous ice nucleation on/in liquid aqueous aerosol particles, which subsequently grow into supermicron-sized ice crystals by condensing water vapour.
Water-activity-based ice nucleation theory can be employed to predict homogeneous ice nucleation temperatures and corresponding ice nucleation rate coefficients for aqueous solution droplets without explicit knowledge of the nature of the solute (Koop et al., 2000; Koop and Zobrist, 2009). While for known mixture compositions the ice melting temperature and the corresponding equilibrium water activity can be measured and/or parameterised precisely (Koop et al., 2000; Koop, 2004; Knopf and Rigg, 2011), the same level of information is not accessible experimentally in the case of supercooled aqueous solution droplets, which exhibit homogeneous freezing of ice at a temperature lower than the corresponding melting point, denoted as $T_{\mathrm{hom}}$. As is well understood in the case of the ice melting process, with the melting temperature being a function of aqueous solution composition (melting point depression), similar behaviour is observed in droplet freezing experiments for the composition and temperature dependence of the homogeneous freezing process. However, the water activity at the freezing temperature is typically not accessible in experiments and/or subject to relatively large uncertainty.

Koop et al. (2000) suggest that $a_{\mathrm{w}}$ at the homogeneous freezing temperature $T_{\mathrm{hom}}\left(x_{\mathrm{org}}\right)$ can be obtained from the corresponding $a_{\mathrm{w}}$ determined at the melting temperature $T_{\mathrm{m}}\left(x_{\mathrm{org}}\right)$ of the solution at the same composition with the assumption that $a_{\mathrm{w}}$ does not change significantly over the temperature difference from $T_{\mathrm{m}}\left(x_{\mathrm{org}}\right)$ to $T_{\mathrm{hom}}\left(x_{\mathrm{org}}\right)$. This approach has been tested and shown to be a good approximation for a variety of inorganic solutions (Koop et al., 2000; Koop, 2004), but may lead to significant errors in predictions of the homogeneous freezing temperatures for aqueous organic solutions. Figure 6 shows $a_{\mathrm{w}}$ at melting and freezing conditions for aqueous organic solutions investigated in this work. The $T_{\text {hom }}\left(x_{\mathrm{org}}\right)$ and $T_{\mathrm{m}}\left(x_{\mathrm{org}}\right)$ temperatures for the investigated organic solutions are measured using the different measurement techniques stated in this paper. The $a_{\mathrm{w}}$ data for the ice melting curve are calculated using the parameterisation by Koop and Zobrist (2009). By applying the assumption that solutions do not show significant change in $a_{\mathrm{w}}$ with temperature from $T_{\mathrm{m}}\left(x_{\mathrm{org}}\right)$ to $T_{\mathrm{hom}}\left(x_{\mathrm{org}}\right)$, i.e. neglecting the temperature dependence, the $a_{\mathrm{w}}$ values evaluated this way show considerable scatter around the ice-freezing curve in Fig 6a. The homogeneous ice freezing curve, shown as a dashed black line in Fig. 6, is calculated by shifting the melting curve by $\Delta a_{\mathrm{w}}=0.313$, as suggested by Koop and Zobrist (2009). The $a_{\mathrm{w}}$ data derived with this assumption in most cases lie below the ice freezing curve. This result could be interpreted as freezing occurring at lower temperatures than predicted by the water-activity-based ice nucleation theory for the known mixture compositions in Fig. 6a. However, since the water-activity-based freezing curve parameterisation is actually very successful in describing the freezing behaviour of many inorganic solutions, for which the experimental or predicted temperature dependence in water activity is small, it is more likely the case that assuming constant 

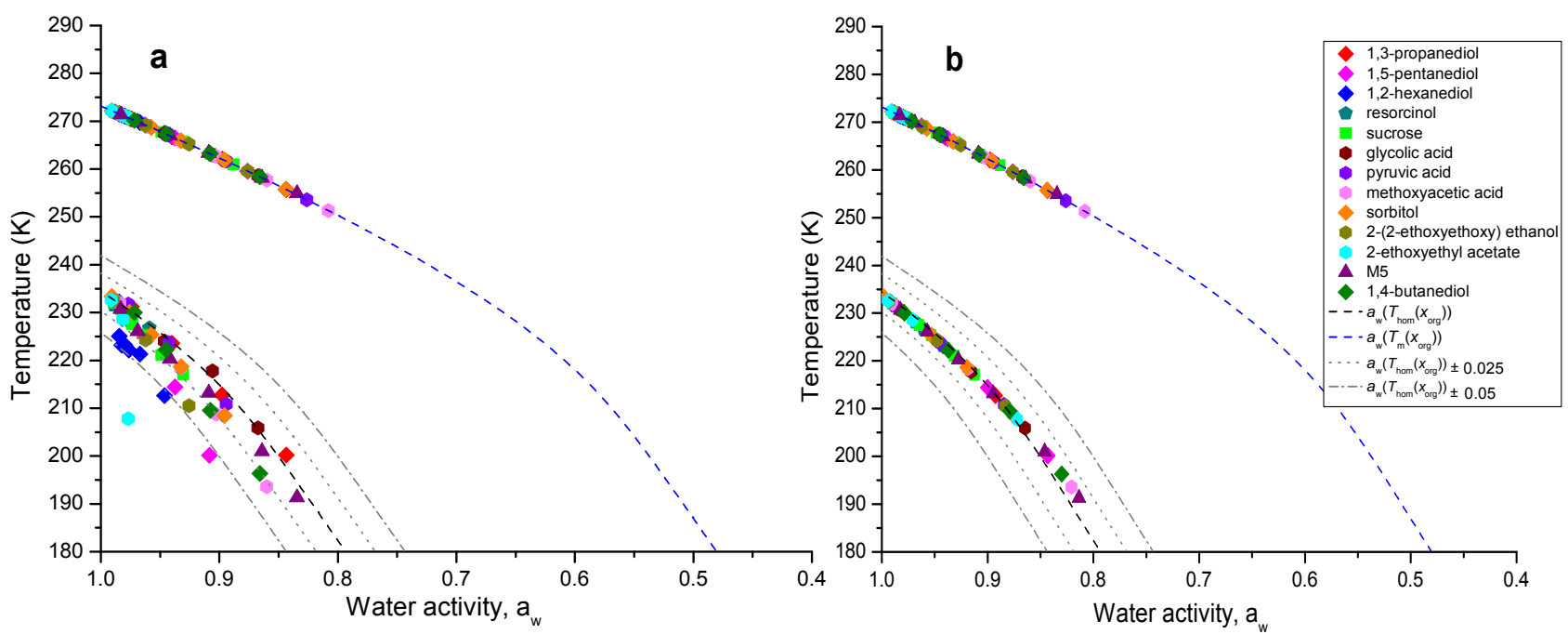

Figure 6. Homogeneous freezing $T_{\mathrm{hom}}\left(x_{\mathrm{org}}\right)$ and melting points $T_{\mathrm{m}}\left(x_{\mathrm{org}}\right)$ as a function of $a_{\mathrm{W}}$ for various aqueous organic solutions. The blue dashed line in $(\mathbf{a}, \mathbf{b})$ is the homogeneous ice melting curve $\left(T_{\mathrm{m}}\right)$ (Koop and Zobrist, 2009). The black dashed line is the homogeneous ice freezing curve $\left(T_{\mathrm{hom}}\right)$ calculated by shifting the melting curve by $\Delta a_{\mathrm{W}}=0.313$ (Koop and Zobrist, 2009). The grey dotted line and grey dash-dotted lines indicate a deviation of 2.5 and $5 \%$ in $a_{\mathrm{w}}$, respectively. In (a), $a_{\mathrm{w}}$ at $T_{\mathrm{hom}}\left(x_{\mathrm{org}}\right)$ is taken to be equal as $a_{\mathrm{w}}$ determined at $T_{m}\left(x_{\mathrm{org}}\right)$ i.e. with the assumption that there is no significant change in $a_{\mathrm{w}}$ with temperature from $T_{\mathrm{m}}\left(x_{\mathrm{org}}\right)$ to $T_{\mathrm{hom}}\left(x_{\mathrm{org}}\right)$. In (b), $a_{\mathrm{W}}$ at $T_{\mathrm{m}}\left(x_{\text {org }}\right)$ is determined using Eq. (3) and the corresponding $a_{\mathrm{w}}$ at the freezing temperature is estimated by using Eq. (3) at $T_{\mathrm{hom}}\left(x_{\mathrm{org}}\right)$ with a constant $\Delta a_{\mathrm{W}}=0.313$ added to the $a_{\mathrm{W}}$ value determined on the melting curve.

water activity from $T_{\mathrm{m}}\left(x_{\mathrm{org}}\right)$ to $T_{\mathrm{hom}}\left(x_{\mathrm{org}}\right)$ is the reason for the apparent discrepancy.

Figure $6 \mathrm{~b}$ shows the same experimental homogeneous freezing data, but in contrast to Fig 6a, the corresponding water activities at the freezing temperature are estimated by using Eq. (3) at $T_{\text {hom }}\left(x_{\text {org }}\right)$ with a constant $\Delta a_{\mathrm{w}}=0.313$ added to the $a_{\mathrm{w}}$ value determined on the melting curve for the same mixture. With this method of $a_{\mathrm{w}}$ data evaluation, the experimental data show much less scatter and an outline in good approximation of a single "experimental" freezing curve. This freezing curve described by the ensemble of aqueous organic solution data is in relatively good agreement with the estimated homogeneous freezing curve according to Koop and Zobrist (2009). A slight, yet systematic deviation of the experimental data towards higher freezing temperatures/lower water activities is found, especially for the freezing temperatures below $220 \mathrm{~K}$. These deviations may result in significantly lower values of homogeneous nucleation rate coefficients $\left(J_{\text {hom }}\right)$ (Knopf and Rigg, 2011). A change of $a_{\mathrm{w}}$ by 0.025 may result in a change of $J_{\text {hom }}$ by six orders of magnitude, which may significantly affect predictions of the onset of ice crystal formation in cloud microphysical models. A difference of three orders of magnitude in $J_{\text {hom }}$ could delay or accelerate homogeneous ice nucleation by about an hour in an atmospheric cloud formation simulation as discussed in Knopf and Rigg (2011).

The strong increase of $a_{\mathrm{w}}$ with decreasing temperature of aqueous M5 and 2-(2-ethoxyethoxy)ethanol solutions at low temperatures and high solute concentrations has conse- quences for the hygroscopic growth of these systems at low temperatures. First, the water uptake assuming thermodynamic equilibrium between the gas and the condensed phase will be much smaller. Second, the low water content at these low temperatures will promote high viscosities or even glass formation leading in addition to kinetic limitations of water uptake.

\section{Conclusions}

Water activity measurements for selected atmospherically relevant aqueous organic systems were carried out using different experimental techniques with the aim of covering a broad concentration and temperature range. Hygroscopicity measurements of single levitated aerosol particles with an electrodynamic balance cover RH between 10 and $90 \%$ RH and temperature from 200 to $300 \mathrm{~K}$. DSC measurements provide the melting and freezing point data at various solution concentrations and can be used to derive compositionand temperature-dependent water activities. To complement these measurements, total gas phase pressure measurements were performed for aqueous organic mixtures. The measured $a_{\mathrm{W}}$ data obtained from the different experiments are consistent with each other and reveal that organic solutes exhibit differing water activity temperature dependence; both substantially increasing and decreasing $a_{\mathrm{w}}$ values with decreasing temperatures below $298 \mathrm{~K}$ are observed.

More accurate $a_{\mathrm{w}}$ data at low temperatures are needed in the context of applications of homogeneous ice nucleation theory at upper tropospheric temperatures. The experiments 
presented in this study provide new equilibrium data sets useful for the development and improvement of thermodynamic activity coefficient models, such as UNIFAC (UNIquac Functional group Activity Coefficients) and AIOMFAC (Aerosol Inorganic-Organic Mixtures Functional groups Activity Coefficients by Zuend et al., 2011). For electrolyte-free organic and organic-water mixtures the AIOMFAC model uses a group-contribution approach based on UNIFAC. We present in a companion paper (Ganbavale et al., 2014) a new, improved parameterisation of AIOMFAC that makes, in addition to published data, use of the data collected in this study. In turn, improved thermodynamic models can be used for more accurate predictions of the temperature dependence of activity coefficients of water and other solution constituents, as well as equilibrium compositions of multiphase systems for mixtures and environmental conditions, for which experimental data are unavailable.

Acknowledgements. This work was supported by the Swiss National Foundation, project 200020-125151 and by the CCES projects IMBALANCE and OPTIWARES funded by the ETH Domain.

Edited by: D. Knopf

\section{References}

Abrams, D. S. and Prausnitz, J. M.: Statistical thermodynamics of liquid mixtures: a new expression for the excess Gibbs energy of partly or completely miscible systems, AIChE J., 21, 116-128, 1975.

Baynard, T., Garland, R., Ravishankara, A., Tolbert, M., and Lovejoy, E.: Key factors influencing the relative humidity dependence of aerosol light scattering, Geophys. Res. Lett., 33, L06813, doi:10.1029/2005GL024898, 2006.

Bones, D., Reid, J., Lienhard, D., and Krieger, U.: Comparing the mechanism of water condensation and evaporation in glassy aerosol, P. Natl. Acad. Sci. USA, 109, 11613-11618, 2012.

Carrico, C., Kus, P., Rood, M., Quinn, P., and Bates, T.: Mixtures of pollution, dust, sea salt, and volcanic aerosol during ACE-Asia: Radiative properties as a function of relative humidity, J. Geophys. Res., 108, 8650, doi:10.1029/2003JD003405, 2003.

Ciobanu, V., Marcolli, C., Krieger, U., Weers, U., and Peter, T.: Liquid- Liquid Phase Separation in Mixed Organic/Inorganic Aerosol Particles, J. Phys. Chem. A., 113, 10966-10978, doi:10.1021/jp905054d, 2009.

Clegg, S. L., Brimblecombe, P., and Wexler, A. S.: Thermodynamic model of the system $\mathrm{H}^{+}-\mathrm{NH}_{4}^{+}-\mathrm{SO}_{4}^{2-}-\mathrm{NO}_{3}^{-}-\mathrm{H}_{2} \mathrm{O}$ at tropospheric temperatures, J. Phys. Chem. A, 102, 2137-2154, 1998.

Cziczo, D. J., DeMott, P. J., Brooks, S. D., Prenni, A. J., Thomson, D. S., Baumgardner, D., Wilson, J. C., and Kreidenweis, S. M.and Murphy, D. M.: Observations of organic species and atmospheric ice formation, Geophys. Res. Lett., 31, L12116, doi:10.1029/2004GL019822, 2004.

DeMott, P. J., Cziczo, D. J., Prenni, A. J., Murphy, D. M., Kreidenweis, S. M., Thomson, D. S., Borys, R., and Rogers, D. C.:
Measurements of the concentration and composition of nuclei for cirrus formation, P. Natl. Acad. Sci., 100, 14655-14660, 2003.

Dormidontova, E. E.: Role of competitive PEO-water and waterwater hydrogen bonding in aqueous solution PEO behavior, Macromolecules, 35, 987-1001, 2002.

Dormidontova, E. E.: Influence of end groups on phase behavior and properties of PEO in aqueous solutions, Macromolecules, 37, 7747-7761, 2004.

Fredenslund, A., Jones, R. L., and Prausnitz, J. M.: GroupContribution Estimation of Activity Coefficients in Nonideal Liquid Mixtures, AIChE J., 21, 1086-1099, 1975.

Fuzzi, S., Andreae, M. O., Huebert, B. J., Kulmala, M., Bond, T. C., Boy, M., Doherty, S. J., Guenther, A., Kanakidou, M., Kawamura, K., Kerminen, V.-M., Lohmann, U., Russell, L. M., and Pöschl, U.: Critical assessment of the current state of scientific knowledge, terminology, and research needs concerning the role of organic aerosols in the atmosphere, climate, and global change, Atmos. Chem. Phys., 6, 2017-2038, doi:10.5194/acp-62017-2006, 2006.

Ganbavale, G., Zuend, A., Marcolli, C., and Peter, T.: Improved AIOMFAC model parameterisation of the temperature dependence of activity coefficients for aqueous organic mixtures, Atmos. Chem. Phys. Discuss., 14, 16907-16995, doi:10.5194/acpd-14-16907-2014, 2014.

Jimenez, J. L., Canagaratna, M.R.and Donahue, N. M., Prevot, A. S. H., Zhang, Q., Kroll, J. H., DeCarlo, P. F., Allan, J. D., Coe, H., Ng, N. L., Aiken, A. C., Docherty, K., Ulbrich, I., Grieshop, A., Robinson, A. L.and Duplissy, J., Smith, J. D., Wilson, K., Lanz, V. A. Hueglin, C., Sun, Y., Tian, J., Laaksonen, A., Raatikainen, T., Rautiainen, J., Vaattovaara, P., Ehn, M., Kulmala, M., Tomlinson, J. M., Collins, D., Cubison, M., Dunlea, E., Huffman, J., Onasch, T., Alfarra, M., Williams, P., Bower, K., Kondo, Y., Schneider, J., Drewnick, F., Borrmann, S., Weimer, S., Demerjian, K., Salcedo, D., Cottrell, L., Griffin, R., Takami, A., Miyoshi, T., Hatakeyama, S., Shimono, A., Sun, J. Y., Zhang, Y. M., Dzepina, K., Kimmel, J. R., Sueper, D., Jayne, J. T., Herndon, S. C., Trimborn, A. M., Williams, L. R., Wood, E., Middlebrook, A. M., Kolb, C., Baltensperger, U., and Worsnop, D. R.: Evolution of organic aerosols in the atmosphere, Science, 326, 1525-1529, doi:10.1126/science.1180353, 2009.

Kanakidou, M., Seinfeld, J. H., Pandis, S. N., Barnes, I., Dentener, F. J., Facchini, M. C., Van Dingenen, R., Ervens, B., Nenes, A., Nielsen, C. J., Swietlicki, E., Putaud, J. P., Balkanski, Y., Fuzzi, S., Horth, J., Moortgat, G. K., Winterhalter, R., Myhre, C. E. L., Tsigaridis, K., Vignati, E., Stephanou, E. G., and Wilson, J.: Organic aerosol and global climate modelling: a review, Atmos. Chem. Phys., 5, 1053-1123, doi:10.5194/acp-5-1053-2005, 2005.

Kjellander, R. and Florin, E.: Water structure and changes in thermal stability of the system poly (ethylene oxide)-water, J. Chem. Soc., Faraday Trans. 1, 77, 2053-2077, 1981.

Knopf, D. and Rigg, Y.: Homogeneous ice nucleation from aqueous inorganic/organic particles representative of biomass burning: Water activity, freezing temperatures, nucleation rates, J. Phys. Chem. A, 115, 762-773, doi:10.1021/jp109171g, 2011.

Knopf, D., Luo, B., Krieger, U., and Koop, T.: Thermodynamic dissociation constant of the bisulfate ion from Raman and ion interaction modeling studies of aqueous sulfuric acid 
at low temperatures, J. Phys. Chem. A., 107, 4322-4332, doi:10.1021/jp027775+, 2003.

Knopf, D. A. and Alpert, P. A.: A water activity based model of heterogeneous ice nucleation kinetics for freezing of water and aqueous solution droplets, Faraday Discuss., 165, 513-534, 2013

Knopf, D. A. and Lopez, M. D.: Homogeneous ice freezing temperatures and ice nucleation rates of aqueous ammonium sulfate and aqueous levoglucosan particles for relevant atmospheric conditions, Phys. Chem. Chem. Phys., 11, 8056-8068, 2009.

Koop, T.: Homogeneous ice nucleation in water and aqueous solutions, Z. Phys. Chem., 218, 1231-1258, doi:10.1524/zpch.218.11.1231.50812, 2004.

Koop, T. and Zobrist, B.: Parameterizations for ice nucleation in biological and atmospheric systems, Phys. Chem. Chem. Phys., 11, 10 839-10 850, 2009.

Koop, T., Luo, B., Tsias, A., and Peter, T.: Water activity as the determinant for homogeneous ice nucleation in aqueous solutions, Nature, 406, 611-614, doi:10.1038/35020537, 2000.

Krieger, U., Colberg, C., Weers, U., Koop, T., and Peter, T.: Supercooling of single $\mathrm{H}_{2} \mathrm{SO}_{4} / \mathrm{H}_{2} \mathrm{O}$ aerosols to $158 \mathrm{~K}$ : No evidence for the occurrence of the octrahydrate, Geophys. Res. Lett, 27, 2097-2100, doi:10.1029/2000GL011613, 2000.

Krieger, U. K., Marcolli, C., and Reid, J. P.: Exploring the complexity of aerosol particle properties and processes using single particle techniques, Chem. Soc. Rev., 41, 6631-6662, 2012.

Lohmann, J., Joh, R., and Gmehling, J.: From UNIFAC to modified UNIFAC (Dortmund), Ind. Eng. Chem. Res., 40, 957-964, doi:10.1021/ie0005710, 2001.

Marcolli, C. and Krieger, U. K.: Phase changes during hygroscopic cycles of mixed organic/inorganic model systems of tropospheric aerosols, J. Phys. Chem. A, 110, 1881-1893, doi:10.1021/jp0556759, 2006.

Marcolli, C. and Peter, T.: Water activity in polyol/water systems: new UNIFAC parameterization, Atmos. Chem. Phys., 5, 15451555, doi:10.5194/acp-5-1545-2005, 2005.

Marcolli, C., Luo, B. P., Peter, T., and Wienhold, F. G.: Internal mixing of the organic aerosol by gas phase diffusion of semivolatile organic compounds, Atmos. Chem. Phys., 4, 2593 2599, doi:10.5194/acp-4-2593-2004, 2004.

Mikhailov, E., Vlasenko, S., Martin, S., Koop, T., and Pöschl, U.: Amorphous and crystalline aerosol particles interacting with water vapor: conceptual framework and experimental evidence for restructuring, phase transitions and kinetic limitations, Atmos. Chem. Phys, 9, 9491-9522, 2009.

Ming, Y. and Russell, L.: Thermodynamic equilibrium of organicelectrolyte mixtures in aerosol particles, AIChE J., 48, 13311348, doi:10.1002/aic.690480619, 2002.

Murata, K.-i. and Tanaka, H.: General nature of liquid-liquid transition in aqueous organic solutions, Nat. Commun., 4, 1-8, 2013.

Murphy, D. and Koop, T.: Review of the vapour pressures of ice and supercooled water for atmospheric applications, Q. J. R. Meteorol. Soc., 131, 1539-1565, doi:10.1256/qj.04.94, 2005.

Murphy, D., Cziczo, D., Froyd, K., Hudson, P., Matthew, B., Middlebrook, A., Peltier, R., Sullivan, A., Thomson, D., and Weber, R.: Single-particle mass spectrometry of tropospheric aerosol particles, J. Geophys. Res., 111, D23S32, doi:10.1029/2006JD007340, 2006.
Murphy, D., Cziczo, D., Hudson, P., and Thomson, D.: Carbonaceous material in aerosol particles in the lower stratosphere and tropopause region, J. Geophys. Res., 112, D04203, doi:10.1029/2006JD007297, 2007.

Novakov, T., Hegg, D., and Hobbs, P.: Airborne measurements of carbonaceous aerosols on the East Coast of the United States, J. Geophys. Res., 102, 30023-30030, doi:10.1029/97JD02793, 1997.

Peter, T., Marcolli, C., Spichtinger, P., Corti, T., Baker, M. B., and Koop, T.: When dry air is too humid, Science, 314, 1399-1402, 2006.

Reid, J., Dennis-Smither, B., Miles, R., Hanford, K., and Homer, C.: The morphology of aerosol particles consisting of hydrophobic and hydrophilic phases: hydrocarbons, alcohols and fatty acids as the hydrophobic component, Phys. Chem. Chem. Phys., 13, 15559-15572, doi:10.1039/c1cp21510h, 2011.

Roberts, G., Artaxo, P., Zhou, J., Swietlicki, E., and Andreae, M.: Sensitivity of CCN spectra on chemical and physical properties of aerosol: A case study from the Amazon Basin, J. Geophys. Res., 107, 8070, doi:10.1029/2001JD000583, 2002.

Rodebush, W.: The freezing points of concentrated solutions and the free energy of solutions of salts., J. Am. Chem. Soc., 40, 1204 1213, doi:10.1021/ja02241a008, 1918.

Salabat, A.: Liquid-liquid equilibrium in the ternary systems triethylene glycol+ salts+ water at different temperatures: Experimental determination and correlation, Fluid Phase Equilibr., 288, 63-66, 2010.

Saxena, P. and Hildemann, L.: Water-soluble organics in atmospheric particles: A critical review of the literature and application of thermodynamics to identify candidate compounds, J. Atmos. Chem., 24, 57-109, 1996.

Saxena, P. and Hildemann, L. M.: Water absorption by organics: Survey of laboratory evidence and evaluation of UNIFAC for estimating water activity, Environ. Sci. Technol., 31, 3318-3324, 1997.

Song, M., Marcolli, C., Krieger, U., Zuend, A., and Peter, T.: Liquid-liquid phase separation and morphology of internally mixed dicarboxylic acids/ammonium sulfate/water particles, Atmos. Chem. Phys., 12, 2691-2712, doi:10.5194/acp-12-26912012, 2012.

Tang, I. and Munkelwitz, H.: Composition and temperature dependence of the deliquescence properties of hygroscopic aerosols, Atmos. Environ. Part A, 27, 467-473, 1993.

Yamasoe, M., Artaxo, P., Miguel, A., and Allen, A.: Chemical composition of aerosol particles from direct emissions of vegetation fires in the Amazon Basin: water-soluble species and trace elements, Atmos. Environ., 34, 1641-1653, 2000.

Zieger, P., Fierz-Schmidhauser, R., Weingartner, E., and Baltensperger, U.: Effects of relative humidity on aerosol light scattering: results from different European sites, Atmos. Chem. Phys, 13, 10609-10631, 2013.

Zobrist, B., Weers, U., and Koop, T.: Ice nucleation in aqueous solutions of poly [ethylene glycol] with different molar mass, J. Chem. Phys., 118, 10254, doi:10.1063/1.1571818, 2003.

Zobrist, B., Marcolli, C., Pedernera, D. A., and Koop, T.: Do atmospheric aerosols form glasses?, Atmos. Chem. Phys., 8, 52215244, doi:10.5194/acp-8-5221-2008, 2008. 
Zobrist, B., Soonsin, V., Luo, B., Krieger, U., Marcolli, C., Peter, T., and Koop, T.: Ultra-slow water diffusion in aqueous sucrose glasses, Phys. Chem. Chem. Phys., 13, 3514-3526, doi:10.1039/c0cp01273d, 2011.
Zuend, A., Marcolli, C., Booth, A. M., Lienhard, D. M., Soonsin, V., Krieger, U. K., Topping, D. O., McFiggans, G., Peter, T., and Seinfeld, J. H.: New and extended parameterization of the thermodynamic model AIOMFAC: calculation of activity coefficients for organic-inorganic mixtures containing carboxyl, hydroxyl, carbonyl, ether, ester, alkenyl, alkyl, and aromatic 25 functional groups, Atmos. Chem. Phys., 11, 9155-9206, doi:10.5194/acp11-9155-2011, 2011. 